\title{
EL CONFLICTO EN SIRIA (2011-2014) A LA LUZ DEL DERECHO INTERNACIONAL Y DE LA (GEO)POLÍTICA
}

\author{
Cesáreo Gutiérrez Espada ${ }^{1}$ \\ Universidad de Murcia (UMU)
}

\begin{abstract}
Resumen:
El conflicto sirio (2011-2014...) constituye una amenaza a la paz y seguridad internacionales. En él, se han cometido atrocidades susceptibles de permitir la invocación del concepto de la Responsabilidad de Proteger. El Consejo de Seguridad no ha impedido, en aplicación de uno u otro concepto, la catástrofe humanitaria en Siria. En ambos casos, el veto de los miembros permanentes del Consejo lo ha impedido. Otra vez más, la práctica internacional revela que solo con una reforma profunda del sistema de seguridad colectiva será posible dotar de pleno efecto útil a la Responsabilidad de Proteger y aun al mismísimo capítulo VII de la Carta de Naciones Unidas.
\end{abstract}

Palabras clave: Capítulo VII, Consejo de Seguridad, derecho de veto, Estado Islámico, Siria y la Unión Europea, sistema de seguridad colectiva.

Title in English: "The International Conflict in Syria (2011-2014) between International Law and (Geo)Politics"

\begin{abstract}
:
The Syrian conflict (2011-2014) is a threat to the maintenance of peace and international security. In the context of this conflict, many atrocities have been committed which could thus facilitate the use of the concept of Responsibility to Protect. The Security Council has failed to adopt the adequate measures, because of the veto power of two permanent members. Thereby, only a deep reform of the veto right can permit the practical development of the concept of Responsibility to Protect, as well as the chapter VII of the United Nations Charter.
\end{abstract}

Keywords: Chapter VII, European Union and Syria, Islamic State, veto right, Security Council, collective security system.

\section{Copyright $@$ C UNISCI, 2015.}

Las opiniones expresadas en estos artículos son propias de sus autores, y no reflejan necesariamente la opinion de UNISCI. The views expressed in these articles are those of the authors, and do not necessarily reflect the views of UNISCI.

\footnotetext{
${ }^{1}$ Cesáreo Gutiérrez Espada es Catedrático de Derecho Internacional Público y Relaciones Internacionales en la Universidad de Murcia.

E-mail: cgutesp@um.es.
} 


\section{El conflicto en Siria}

Cuando en marzo de 2011 estallaron en Siria las primeras revueltas contra el régimen, Bashar Al-Assad era (y es) el Presidente de Siria. Heredó el poder de su padre, Hafez Al-Assad, al morir este en junio de 2000.

Hafez Al-Assad, a su vez, había llegado al poder en 1970 con un golpe de Estado, haciéndose con el liderazgo indiscutible del partido Baath (Partido Socialista Árabe). Expulsó del partido (o eliminó sin más) a todos sus rivales políticos, poniendo en los cargos de responsabilidad, en éste y en el entramado institucional del régimen, a familiares cercanos y personas de su total confianza. El 12 de marzo de 2014, el Tribunal General de la Unión Europea, confirmando la legalidad de un reglamento del Consejo que incluía en la lista de personas objeto de medidas restrictivas a Bouchra Al-Assad, hermana del actual Presidente de la República Árabe Siria y esposa, viuda ya en ese momento, de otro miembro del Gobierno sirio, Asif Shawkat, afirma expresamente en su sentencia:

"No obstante, el mero hecho de que la demandante sea la hermana del Sr. Bashar Al-
Assad basta para que el Consejo pueda considerar que está vinculada a los dirigentes de
Siria en el sentido de las disposiciones mencionadas en el apartado 88 de la presente
sentencia, sobre todo porque la existencia en dicho país de una tradición de gestión
familiar del poder es un hecho notorio que puede ser tenido en cuenta por el Consejo".

El Presidente Hafez Al-Assad no permitió disidencia política alguna, reprimiendo con dureza a sus opositores. El aumento en el país, década de los 70, de quienes, liderados por los Hermanos Musulmanes, propiciaban un derrocamiento del régimen y la instauración del Estado islámico acabó en un baño de sangre ("masacre de Hama") en febrero de 1982, pereciendo, las cifras varían, entre $20.000^{3}$ y 30.000 personas ${ }^{4}$.

Desde el golpe de Estado de Hafez Al-Assad, el Partido Baath y las Fuerzas de Seguridad quedaron en manos de la familia Al-Assad, sus amigos y colaboradores, todos pertenecientes a la minoría aluí (rama del chiísmo), un $12 \%$ del total de la población, Junto a ésta, hay otras minorías, como los cristianos y los propios chiitas, en un país mayoritariamente sunní.

A la muerte de su padre, Bashar Al-Assad, formado en Occidente, le sucede en todos sus cargos. Al comenzar su liderazgo, promete reformas políticas y económicas ("la primavera de Damasco"), pero las escasas reformas que se llevaron a cabo fueron revocadas no mucho después, permaneciendo Siria por tanto en el marco del modelo autocrático de décadas anteriores.

El actual conflicto armado en Siria arranca el 6 de marzo de 2011. Ese día un grupo de adolescentes fue detenido en Dara, al Sur del país, por dibujar en una pared un graffiti contra el régimen. Esta detención generó grandes manifestaciones en la ciudad, que fueron reprimidas por los cuerpos y fuerzas de policía. Se abrió fuego contra los civiles. Las protestas se extendieron por todo el país en cuestión de meses.

Aunque el régimen insiste en afirmar lo contrario, no parece que estas protestas iniciales tuviesen una motivación ideológico-política ni estuviesen planificadas. Lo que parece, por el contrario, es que nos hallamos, como en Egipto, Túnez, Libia o Yemen en esos momentos,

\footnotetext{
${ }^{2}$ Sentencia del TG (Sala sexta), de 12 de marzo de 2014 (as. T-202/12), apartado 96 www.curia.europa.eu.

3 "Una guía del conflicto sirio: diez preguntas claves" CIDOB, p. 1, http://www.cidob.org, pp. 1-9, dossiers.

4 Riestra, Laura: "Ocho puntos para comprender el conflicto en Siria", $A B C$, 10 Junio 2012, en http://www.abc.es/20120610/internacional/abci-siria-evolucion-conflicto-201206061519.html.
} 
ante una manifestación más de lo que se ha dado en llamar "primavera árabe", revuelta popular contra regímenes autocráticos y corruptos.

Lo que empezó así se descompuso con rapidez. La represión brutal de las protestas genera un movimiento de organización y oposición armada, civil y militar, este último componente nutrido por los desertores de los cuerpos y fuerzas de seguridad del régimen y aún del ejército mismo, alertados por el uso excesivo de la fuerza contra la población. El primer incidente de rebelión armada abierta se produce en junio de 2011, en las proximidades de la frontera con Turquía: civiles locales se hicieron con las armas de una comisaría de policía tras los disparos contra manifestantes de las fuerzas del régimen; parte de la unidad del ejército enviada a la zona deserta y se une a los civiles armados en su lucha contra las fuerzas de seguridad. Septiembre de 2011 (Homs y Jabel al Zaqiya), enero de 2012 (suburbios del este de la capital, Damasco), julio de 2012 (Alepo) (...) El conflicto se extiende por toda Siria, con una oposición armada (armas y munición que provienen inicialmente de las capturadas a los cuerpos y fuerzas de seguridad y del ejército pero que también se van adquiriendo por la oposición al régimen con fondos aportados por otros Estados).

En julio de 2012, el Comité Internacional de la Cruz Roja califica ya la situación en Siria como de conflicto armado interno (guerra civil). Un conflicto, por lo demás, como enseguida veremos que se ramifica o diversifica en el plano interno, de un lado, y, de otro se internacionaliza.

\subsection{Los contendientes}

Contra el régimen de Basher Al-Assad luchan numerosos grupos armados. Analistas del conflicto, como Charles Lister, estiman que hay aproximadamente mil grupos armados activos en Siria ${ }^{6}$, a veces formando alianzas ad hoc y otras compitiendo entre ellos ${ }^{7}$; todos tienen un objetivo común: derrocar el régimen, pero no tienen proyecto político alternativo alguno en el que coincidan. Es útil, a mi juicio, distinguir (entre los opositores al régimen sirio), dos grandes grupos:

A) De un lado, los grupos de actores políticos, dentro y fuera de Siria, que se llaman comúnmente "de la oposición". Inicialmente se unieron varios de ellos en el Consejo Nacional Sirio (marzo 2011). Su falta de influencia en los grupos armados sobre el terreno y las luchas internas forzaron, por medio de un intenso trabajo de la diplomacia internacional, su sustitución, en noviembre de 2012, por el Consejo Nacional de la Revolución Siria y las Fuerzas de la Oposición, en un intento de ampliar la base de la oposición política al régimen. El Consejo es apoyado por el Ejército Sirio Libre, integrado por desertores y voluntarios que decae y se deshilacha (...).

B) De otro lado, están los grupos yihadistas que se han ido convirtiendo en el elemento dominante, y más peligroso para Occidente, en la guerra civil. Cuatro, parece, son los grupos más significativos, con diferencias entre sí pero todos con una meta común, la instauración en Siria de un Estado islámico con la sharia como Ley:

\footnotetext{
${ }^{5}$ Véase por ejemplo: Blanc Altemir, Antonio: "La comunidad internacional ante la llamada 'primavera árabe"”, en Gutiérrez Espada, Cesáreo (Director) y Cervell Hortal María José (coord.) (2012): Nosotros y el Islam, Diego Marín Librero-Editor, pp. 46-84; Martínez Sánchez, R.P.: “La denominada 'primavera árabe' en el Norte de África, con especial referencia a Marruecos, y sus repercusiones para la seguridad europea”, en Ibid., pp. 85-114. ${ }^{6}$ CIDOB: "Una guía al conflicto sirio...," op. cit., p. 3.

${ }^{7}$ Por ejemplo: el 12 de mayo de 2014, la agencia Reuter daba cuenta de los enfrentamientos (por el control territorial y las divergencias internas) entre los dos principales grupos yihadistas en Siria, el Estado Islámico de Irak y Siria (ISIS en inglés), hoy ya simplemente Estado Islámico (IS), y el Frente Al-Nusra, con el resultado de un número de muertos mayor en los enfrentamientos de las últimas semanas que los habidos entre las fuerzas del régimen sirio y los rebeldes, http://www.europapress.es.
} 
- El Frente Al-Nusra, grupo afiliado a Al-Qaeda. Creado en enero de 2012, de este grupo destaca sobre todo su implantación en la práctica totalidad del territorio de Siria (está presente y activo en 11 de sus 13 regiones).

- En abril de 2013, nace el Estado Islámico de Irak y Siria (que en junio de 2013 para a denominarse sin más Estado Islámico), que rompe con el Frente Al-Nusra y crece rápidamente. Tiene sus baluartes en Homs, Raqqa, Abú Kamal y a lo largo de la frontera con Turquía. No se conoce el número total de sus integrantes pero se cree lo forman mayoritariamente yihadistas extranjeros. De hecho más de 12.000 extranjeros se han unido a grupos armados islamistas en Siria e Irak, muy en particular al Estado Islámico; cerca de la mitad de ellos proceden de Marruecos, Argelia y Túnez, pero también de España e Italia. Es el Estado Islámico, desde hace más de un año, la organización que atrae en mayor medida a los yihadistas más radicales reclutados en los países europeos del Mediterráneo occidental $^{8}$.

- A finales del verano de 2013, cerca de 50 grupos armados islamistas se reúnen en las afueras de Damasco y crean Jaysh al Islam (El Ejécito del Islam), con Zahran Allousch, excomandante de Liwaa al Islam, que formaba parte del Ejército Sirio Libre, como líder. Entrevistado por el canal de TV Al Yaziraa, el líder rebelde nos dejó muy claro como ve el futuro del país de imponerse militarmente: las minorías religiosas en Siria son infieles y deben convertirse al Islam; más aún:

"El Islam no puede llegar al poder a través de la democracia, como no puede crecer la uva entre las espinas del endrino".

- Y, finalmente, el Frente Islámico agrupa, desde noviembre de 2013, a varias organizaciones armadas rebeldes, entre las que destacan por su fuerza y eficacia en el combate Ahsrar-al-Saam, las brigadas Suqoor-al-Shaam y Liwaa al Tawheed.

La polarización y división de los opositores al régimen sirio, de un lado, y la creciente influencia en ellos del islamismo radical, de otro, permiten comprender, de una parte, por qué Bashar Al-Assad sigue en el poder aún y, de otra y en íntima relación con ello, por qué Occidente ha ido suavizando hasta el silencio hoy su petición de que Bashar Al-Assad se vaya (...). Como si a todos fuese pareciendo ya mejor que en Siria siga gobernando quien hoy, parece, está un poquito más cerca de la victoria final.

\subsection{Sus amigos ${ }^{10}$}

El régimen sirio cuenta como principales aliados con Rusia e Irán. Rusia defiende su influencia en el único "amigo" susceptible a ella en la región. Irán, diferente ideológicamente

\footnotetext{
${ }^{8}$ Reinares, Fernando: "Siria y la movilización yihadista en tormo al Mediterráneo Occidental”, Comentario Elcano 46/2014, 7 de julio de 2014, pp. 1-2. El profesor Reinares alerta, además, del riesgo de que una parte considerable de estos individuos pueda volver a sus países de origen no solo activos en su compromiso islamista radical sino también bien entrenados en la lucha armada, con lo que la amenaza terroristas en esos países crece (...).

9 "Siria, ¿más ejércitos para seguir luchando?", La voz de Rusia, 11 de noviembre del 2013, en http://spanish.ruvr.ru/2013 11_11/Siria-Mas-ejercitos-para-seguir-peleando-4304/.

${ }^{10}$ Sobre el papel de los diversos Estados, árabes y no árabes, que apoyan o rechazan al régimen sirio véase Kinninmont, J.: "The Syrian conflict anf the geopolitics of the region”, pp. 1-6 (artículo publicado en línea a la espera de su aparición impresa en IEMed Meditarranean Yearbook, en www.iemed.org/medyearbook).
} 
del régimen "secular" sirio, ha prestado un importante apoyo a Damasco ${ }^{11}$, probablemente por dos razones:

- Irán tiene un interés fundamental en mantener su "pasillo" sirio para seguir con su suministro de armas y de recursos a Hezbollah, en el Líbano.

- El conflicto de Siria ha enfatizado la rivalidad entre la República Islámica de Irán y Arabia Saudí en presentarse como los líderes legítimos del Islam. Irán teme que de caer el régimen de Damasco, enemigo de Arabia Saudí, éste país consiga una importante victoria política.

Irán ha utilizado también a grupos armados de Hezbollah para operar sobre el terreno en Siria en apoyo de las fuerza del régimen.

Los "rebeldes" cuentan con el apoyo oficial de Estados árabes, ya se ha apuntado, como Arabia Saudí, pero también de Jordania, Qatar y Turquía. No obstante, la fragmentación de quienes luchan contra Bashar Al-Assad y, sobre todo, la creciente influencia como antes decía de los grupos islamistas radicales ha matizado en los últimos tiempos ese apoyo.

Occidente, con Estados Unidos a la cabeza, barajó incluso una intervención armada limitada contra el gobierno sirio tras el uso de armas químicas en el conflicto, idea que apoyaron el Reino Unido y Francia. El Parlamento británico, sin embargo, no autorizó nada y el mismo Presidente Obama ni siquiera llevó el asunto ante el Congreso.

Desde septiembre de 2013, estos tres países que habían apoyado claramente a ciertos grupos armados de los rebeldes (en particular al Ejército Libre de Siria), descartan una intervención armada por limitada que fuera y se centran en intentar una solución diplomática del conflicto (Conferencia de Ginebra) que no ha tenido finalmente éxito. La posición de Occidente, por lo demás, de claro rechazo al Presidente Bashar Al-Assad, se ha ido deslizando hacia otra de claro rechazo del componente islamista de la rebelión. Tanto que, con ocasión de los excesos cometidos por el Estado islámico ${ }^{12}$, se está formando una coalición impulsada por los Estados Unidos que no descarta atacar con las armas objetivos de este grupo islamista en territorio sirio $^{13}$. Ya el 2 de septiembre de 2014, el Secretario de Defensa de los Estados Unidos, Chuck Hagel, dejó claro que para este país la derrota del Estado islámico pasa por atacarle no solo en Irak sino también en Siria; la "justificación" avanzada de esta posibilidad se encuentra, a tenor de las palabras del Sr. Hagel, en la Estrategia de Seguridad Nacional de los Estados Unidos que contempla el uso preventivo de la fuerza frente a "amenazas inminentes" 14 . Puede añadirse que el lunes 15 de septiembre de 2014 se abrió en París una Conferencia internacional sobre la Paz y Seguridad en Irak, a la que asisten 30 estados, entre ellos los cinco miembros permanentes del Consejo de Seguridad, en la que noticias de agencia dan por hecho la existencia de un acuerdo de todos los participantes sobre el uso "de todos los

\footnotetext{
11 Botón de muestra: el gobierno iraní ha acabado por reconocer que ha enviado a sus Guardianes de la Revolución para asesorar y entrenar a las fuerzas de seguridad y militares del régimen.

${ }^{12}$ Sirva de ejemplo de todas las atrocidades cometidas la decapitación y su difusión en vídeo, en la tercera semana del mes de agosto de 2014, del periodista estadounidense James Foley, secuestrado en Siria en noviembre de 2012. El brutal hecho fue al parecer cometido (ad ex. el diario La Razón de 22 de agosto de 2014, p. 20) por un yihadista británico que lucha en las filas del Estado islámico (véase la prensa escrita, nacional e internacional, de esos días (...).

${ }^{13}$ La coalición, integrada por 10 Estados (Estados Unidos, Reino Unido, Francia, Alemania, Italia, Polonia, Dinamarca, Canadá, Australia y Turquía), contempla bombardeos y el refuerzo a socios locales, descartando un ataque terrestre (El País, 9 de septiembre de 2014, en http://:internacional.elpais.com/internacional/2014/09/05/actualidad/14099/7501_927947html).

14 "El Estado islámico es una amenaza inminente", $A B C, 21$ de agosto de 2014, en http://m.abc.es/internacional/20140821/abcp-hagel-dempsey-rueda-prensa-20140821.html. Repárese, estaríamos pues, parece, en la legítima defensa (preventiva), no en el concepto de Responsabilidad de Proteger.
} 
medios, incluidos los militares" para derrotar en Irak al Estado Islámico ${ }^{15}$ (repárese, que la Conferencia es sobre Irak).

Resulta no poco curiosa la "frustración de los Estados árabes pro-occidentales con los Estados Unidos"16 antes de estos últimos acontecimientos: muy críticos con la "Guerra de Irak" (2003), los Estados del Golfo o Arabia Saudí criticaron sin miramientos el descarte de una intervención armada en Siria; Arabia Saudí en particular conectó su malestar en este sentido con su gesto de protesta inusual de renunciar a su puesto como miembro no permanente del Consejo de Seguridad para el que había sido elegida .

\subsection{Conclusión}

Una conclusión más que evidente aflora de todo lo expuesto: en Siria se desarrolla un conflicto armado interno, que se ha ido internacionalizando paulatinamente con los apoyos de otros Estados a los bandos en lucha.

Ese conflicto, por la zona en la que se desarrolla, por los actores en él implicados, por las violaciones muy graves del Derecho Internacional Humanitario que se han cometido por los dos bandos y por el uso, al menos una vez, de armamento químico, constituye una inequívoca amenaza a la paz y seguridad internacionales.

Ese conflicto ha generado asimismo una catástrofe humanitaria también en la que se han cometido atrocidades como las que permiten invocar la aplicación del concepto de la Responsabilidad de Proteger.

\section{Una respuesta tardía y pobre, la de la comunidad internacional}

\subsection{El Consejo de Seguridad y el capítulo VII de la Carta de Naciones Unidas: "no sabe no contesta"}

Vayamos por partes. En los primeros meses del conflicto, cuando surgieron las primeras alertas y denuncias, se acordó una misión de investigación del Alto Comisionado de Derechos Humanos de las Naciones Unidas para determinar las posibles violaciones allí cometidas ${ }^{17}$ y también el Consejo de Derechos Humanos de Naciones Unidas pidió de manera expresa al Gobierno el fin de los actos de violencia ${ }^{18}$, pero los informes de seguimiento del cumplimiento de esta demanda demostraron que los crímenes de lesa humanidad y crímenes de guerra cometidos, tanto por las fuerzas gubernamentales como por los rebeldes seguían, seguían de hecho aumentando ${ }^{19}$.

Pese a todo ello, la respuesta de la comunidad internacional ha sido muy limitada ${ }^{20}$. Las organizaciones regionales, que tan activamente se movieron en la crisis libia (marzo-octubre

\footnotetext{
15 El País, 15 de septiembre de 2014, también euronews, en http://es.euronews.com, (15/09/2014) y Radio Francia Internacional, en http://www.espanol.rfi.fr).

${ }^{16}$ Kinninmont, Jane: "The Syrian conflict...", op. cit., p. 4.

${ }^{17}$ Informe de 18 de agosto de 2011.

${ }^{18}$ Resolución 19/22 del Consejo de Derechos Humanos, de 23 de marzo de 2012.

${ }^{19}$ Véase el último Informe, distribuido el 25 de septiembre de 2013 (A/HRC/21/32).

${ }^{20}$ Sobre las reacciones de los diversos actores internacionales frente al conflicto en Siria, Arteaga, Félix: "Siria: la lenta marcha hacia la guerra civil", ARI Real Instituto Elcano n ${ }^{\circ}$ 96/2012 (6 de marzo de 2012), pp. 4-9; Pons Rafols, Xavier: "Naciones Unidas y Siria: idea y realidad", ANUE, no 43 (mayo 2012), pp. 5-14; Andrés Saenz de Santamaría, Paz: "Las Naciones Unidas ante el conflicto de Siria”, Documento de Opinión, IEEE, 93/2012 (18 diciembre 2012), pp.1-15; Weckel, Philippe.: "Crise en Syrie, la relance du processus politique", Bulletin Sentinelle, $\mathrm{n}^{\circ}$. 348, (19 de mayo de 2013), pp. 1-12. Sobre la eventual utilización de la fuerza armada por la comunidad internacional, véase Domestici-Met, Marie-José.: "Protecting in Libya on behalf international community", Goettingen Journal of Internacional Law, no 3 (2011), pp. 861-889; Marrero Rocha, Inmaculada:
} 
2011), se mostraban esta vez dubitativas y el Consejo de Seguridad era incapaz de sacar adelante resolución alguna que incluyera medidas coercitivas de entidad suficiente.

El Consejo se reunió el 27 de abril de 2011 para hacer el primer balance de la situación ${ }^{21}$. Enseguida se comprobó la clara división entre sus miembros: mientras el representante británico presionaba para actuar, el ruso alegaba que se trataba de una cuestión interna y que, en tanto en cuanto las dos partes en el conflicto habían usado la violencia no merecía la consideración de amenaza para la paz y seguridad internacionales.

El 29 de abril (2011), el Consejo de Derechos Humanos aprobó la resolución S-16/1 condenando de manera expresa el empleo de la violencia contra los manifestantes.

El 25 de mayo (2011), Francia, Alemania, Portugal y Reino Unido volvieron a intentar que el Consejo de Seguridad se implicara con la cuestión siria, presentando un borrador de resolución que condenaba la situación y en el que figuraba de manera expresa la obligación de Siria de proteger a sus ciudadanos. Nuevamente, Rusia, China, India, Brasil y Sudáfrica afirmaron que la resolución no debería determinar la naturaleza del programa de reformas del Gobierno sirio porque era una cuestión interna y, de hecho, Rusia y China recordaron de manera directa lo ocurrido con la resolución 1973 (2011) en el caso de Libia.

Los partidarios de adoptar una resolución volvían a la carga unos meses después (octubre 2011), presentando un nuevo borrador que pedía el fin de la violencia y la introducción de reformas, así como la opción de barajar sanciones en el caso de que Siria no cumpliera $^{22}$. La propuesta no corrió mejor suerte que las anteriores, rechazándose con cuatro abstenciones (Brasil, India, Líbano y Sudáfrica) y dos votos de miembros permanentes en contra (China y Rusia) ${ }^{23}$. No consiguió hacerles cambiar de opinión la suspensión de la condición de Estado miembro de Siria por la Liga Árabe el 16 de noviembre, ni la imposición por esta organización de sanciones, ni el crítico informe del Consejo de Derechos Humanos ${ }^{24}$ ni la segunda resolución que este adoptó recomendando a los órganos de Naciones Unidas y al Consejo de Seguridad en particular la adopción de medidas ${ }^{25}$.

\footnotetext{
"La responsabilidad de proteger de la comunidad internacional en los casos de Libia y Siria: análisis comparativo", Relaciones Internacionales, $\mathrm{n}^{\mathrm{o}} 22$ (febrero-mayo 2013), pp. 127-148, en http://www.relacionesinternacionales.info; Echeverría, Carlos.: Evolución y perspectivas del conflicto de Siria: el factor islamista, Análisis Del Grupo de Estudios Estratégicos (28 de febrero de 2013(, en http://www.gees.org, pp. 1-4; Saira, Mohammed.: "The UN Security Council and the crisis in Syria", American Society of Internacional Law Insights, vol. 16, $\mathrm{n}^{\mathrm{o}} 11$ (26 de marzo de 2012); Zifcak, Spencer.: "The responsibility to protect after Libya and Syria", Melbourne International Law Journal, n 13 (2012), pp. 1-35. Muy interesantes resultan también las reflexiones de diversos autores que se han incorporado al EJIL Talk http://www.ejiltalk.org: Akande, Dapo.: "The legality of military action in Syria: humanitarian intervention and responsibility to protect", European Journal of International Law Talk (28 de agosto de 2013); Stahn, Carsten.: "Syria and the semantics of intervention, aggression and punishment", EJIL Talk (19 de septiembre de 2013) y, del mismo autor, "Syria, Security resolution 2118 (2013) and peace versus justice: two steps forward, one step back", EJIL Talk (3 de octubre de 2013); Hongiu Koh, H.: "Syria and the law of humanitarian intervention (Part II: International Law and the way forward", EJIL Talk (4 de octubre de 2013) y Hongiu Koh, Harold.: "Syria and the law of humanitarian intervention (Part III: a reply), EJIL Talk (12 de octubre de 2013). Asimismo, Kinninmont, Jane.: "The Syrian Conflict...", op. cit., pp. 1-6.

${ }^{21}$ S/PV.6534, 27 de abril de 2011.

${ }^{22}$ S/PV.6627, 4 de octubre de 2011.

${ }^{23}$ Rusia volvía a afirmar que la resolución no respetaba los conceptos de soberanía, integridad territorial y no intervención (doc. S/PV.6627, 4 de octubre de 2011, p. 3) y dejaba constancia de sus críticas a lo sucedido en Siria (p. 4). Casi idénticos fueron los argumentos chinos

${ }^{24}$ A/HRC/S-17/'/Add.1)

${ }^{25}$ Resolución S.18/1, de 5 de diciembre de 2011.
} 
La Asamblea General de las Naciones Unidas, por su parte, adoptaba el 16 de febrero de 2012 la resolución 66/253A condenando $\operatorname{los}_{\text {hechos }}{ }^{26}$ y el 3 de agosto de 2012 (resolución 66/253B), daba un pequeño toque de atención al Consejo de Seguridad, al alentarlo a examinar medidas apropiadas para la crisis siria (párrafo 9).

¿Qué hubiera el Consejo de Seguridad, al que acusamos de permanecer inactivo, podido (o debido) hacer ante la situación en Siria?

El Consejo, responsable principal según la Carta del mantenimiento de la paz (artículo 24), podría haber declarado esa realidad, lo que preceptivamente determina el artículo 39 de la misma, como paso previo a la adopción de medidas coercitivas e, incluso, en su caso, de medidas coercitivas armadas que acabaran con el conflicto o lo recondujeran a proporciones menos calamitosas. Así lo hizo en Libia (2011), pero como se basó para hacerlo en el concepto de la Responsabilidad de Proteger volveré en su momento sobre ello. En el caso de Siria, no lo ha hecho. Y solo, como veremos, muy tardíamente el Consejo de Seguridad se ha ocupado de este tema. ¿Por qué? Dicho en términos sencillos y prácticos, porque Rusia y China, miembros permanentes ambos del Consejo, se opusieron a adoptar medida significativa alguna.

Y es que en el Derecho internacional vigente el Consejo de Seguridad puede aplicar el Capítulo VII cuando, ante la existencia de un conflicto que a su juicio él califica expresamente ex artículo 39 de la Carta de una "amenaza a la paz y seguridad internacionales", lo considera oportuno pero no está obligado a hacerlo y, en concreto, sus miembros permanentes no tienen, hoy por hoy, obligación jurídica alguna de no hacer uso de su derecho de veto. Si el internacionalista francés que cito me lo permite, diría, como él hace para referirse en concreto a la Responsabilidad de Proteger pero que es perfectamente aplicable al supuesto de la aplicación particular del Capítulo VII mismo, "que no se trata de una postura cínica y que, para ser honestos, lamentamos profundamente haber llegado a esta conclusión" 27 , pero esto es lo que hay y no hay más cera que la que arde. Otra cosa sería, de aceptarse la propuesta del Instituto de Derecho Internacional, en su sesión de Rodas (2011), en la que, tras establecer en su Resolución, que:

"El Consejo de Seguridad no puede autorizar el uso de la fuerza por los Estados miembros o por acuerdos u organismos regionales sino después de haber declarado la existencia de una amenaza contra la paz, ruptura de la paz o acto de agresión”,

considera asimismo que:

"Toda situación de violaciones graves y masivas de los derechos humanos y/o de atentado graves al derecho internacional humanitario debería ser considerada por el Consejo de Seguridad como una amenaza contra la paz respecto de la cual debería tomar de inmediato las medidas que juzgue apropiadas a las circunstancias, incluido el uso de la fuerza, ${ }^{, 28}$.

\footnotetext{
${ }^{26}$ Al respecto, Carswell, Andrew J.: "Unblocking the UN Security Council. The Uniting for Peace Resolution", Journal of Conflict \& Security Law, vol. 18, nº 3 (2013), pp. 453-480.

${ }^{27}$ Pellet, Alain (2013): "What normativity for the Responsability to Protect?", en Chaumette, Anne Laure y Thenouvenin, Jean-Marc (dir.): La Responsabilité de Proteger dix ans aprés/ The Responsability to Protect ten years on, Pédone, París, pp. 185-191, 190.

${ }^{28}$ Résolution de la Dixième Commission (problèmes actuels du récours à la force en droit international), Sousgroupe D (L' autorisation du recours à la force par les Nations Unies), Institut de Droit International, Rapporteur: M. Raúl Emilio Vinuesa, Session de Rhodes 2011, artículos 4 y 6 (cursiva añadida).
} 
Si el Consejo de Seguridad hubiese autorizado, de conformidad con el capítulo VII de la Carta, una intervención armada con la finalidad de detener los enfrentamientos y proteger a la población $^{29}$, este uso de la fuerza en Siria hubiera sido, de acuerdo con el Derecho internacional vigente, y en concreto con la Carta de Naciones Unidas, plena y totalmente legal.

\subsection{La Responsabilidad de Proteger inaplicada}

El concepto de Responsabilidad de Proteger ha sido aceptado por la comunidad internacional $^{30}$. El Documento Final de la Cumbre del Milenio (2005) lo prueba ${ }^{31}$. El Secretario General de Naciones Unidas siete años después (2012) lo ratifica:

"La responsabilidad de proteger proporciona un marco político basado en principios fundamentales del derecho internacional para prevenir el genocidio, los crímenes de guerra, la depuración étnica y los crímenes de lesa humanidad y responder ante ellos. Está claro que el concepto ha sido ampliamente aceptado. Los órganos principales de las Naciones unidas han invocado el concepto entre ellos el Consejo de Seguridad y la Asamblea General"

"Debemos seguir tratando de hacer efectiva la responsabilidad de proteger con mayor eficacia y coherencia. Sigo estando convencido de que es un concepto al que le ha llegado su momento",32

Dicho concepto, y así fue aceptado en el citado Documento Final, incluye tres elementos: el deber de prevenir, el de reaccionar (con medidas coercitivas que pueden llegar, en su caso, a una intervención armada por causa de humanidad) y, en este último caso, el deber de reconstruir.

El Documento Final, en el caso del deber de reaccionar y, en concreto, en los supuestos de intervenciones armadas, supedita éste a una autorización previa del Consejo de Seguridad. Ello implica, en el Derecho vigente, que no se interponga el veto de al menos uno de los cinco miembros permanentes del Consejo; según la práctica, que la CIJ (asunto de Namibia, 1971) considera una norma de Derecho internacional general, la abstención de los miembros permanentes no supone la interposición de un veto ${ }^{33}$.

La práctica internacional revela, asimismo, que la Responsabilidad de Proteger se ha puesto en marcha ya, con medidas coercitivas no armadas y armadas, en varias ocasiones ${ }^{34}$.

\footnotetext{
${ }^{29}$ Acerca de la dimensión humanitaria del mantenimiento de la paz y el uso del Capítulo VII de la Carta con fines de protección véase Gifra Durall, Julia: "Las Operaciones de Paz de Naciones Unidas del capítulo VII: ¿excepción o práctica extendida?”, Revista del IEEE, n. 2/2013, pp. 1-28.

${ }^{30} \mathrm{Se}$ ha dicho incluso que con ello la comunidad internacional esta "postulando su ingreso en el club de los principios estructurales del sistema internacional que deben inspirar la conducta de sus distintos sujetos y que actúan como referentes de la coherencia interna del ordenamiento internacional" Jiménez García, Francisco.: "Contramedidas colectivas, responsabilidad de proteger e inmunidades estatales: visiones caleidoscópicas del Derecho internacional”, en S. Torres Bernárdez, J.C.; Fernández Rozas, C.; Fernández de Casadevante Romaní y A.G. López Martín (coords.) (2013): El Derecho internacional en un mundo multipolar del siglo XXI. Obra homenaje al profesor Luis Ignacio Sánchez Rodríguez, Iprolex, Madrid, pp. 235-264, 248).

${ }^{31}$ A/RES/60/1, Documento Final de la Cumbre Mundial 2005, 24 de octubre de 2005, párrafos 138 y 139.

${ }^{32}$ La responsabilidad de proteger: respuesta oportuna y decisiva. Informe del Secretario General, A/66/874S/2012/578, 25 julio 2012, pp. 18-19 (párrafos 59 y 61) (cursiva añadida).

${ }^{33}$ Dictamen consultivo de 21 de junio de 1971, párrafos 21-22, ICJ Reports 1971, p. 22.

${ }^{34}$ Desde 1989, James Pattison, contabiliza hasta doce "intervenciones humanitarias", con empleo de medios militares, a cargo de Estados (Estados Unidos, Australia, Reino Unido y Francia), grupos de Estados (FranciaReino Unido-Estados Unidos) y Organizaciones internacionales (ECOWAS [Comunidad Económica de Estados de Africa Occidental], OTAN, y Naciones Unidas [incluyendo fuerzas de la Unión Europea]) Humanitarian intervention \& Responsability to Protect. Who should intervene?, Oxford University Press, Oxford, 2010, pp. 12 .
} 
Desde el 2001, año en el que el concepto es aceptado por la CIISE, pero sobre todo desde el año 2005, en el que lo fue con carácter general, lo ha sido en varios casos:

- En la resolución 1970 (2011), de 26 de febrero, el Consejo de Seguridad hizo una referencia explícita a la responsabilidad de proteger. Lamentando la "violación burda y sistemática de los derechos humanos" en el conflicto en Libia, el Consejo exigía que se pusiera fin a la violencia "recordando a las autoridades libias su responsabilidad de proteger a su población" y le impuso una serie de sanciones; decidió también remitir la situación a la CPI.

- El Consejo de Seguridad, en su resolución 1996 (2011) de 8 de julio, estableció una misión de mantenimiento de la paz en Sudán del Sur (UNMISS), que se convirtió finalmente en Estado independiente el 9 de julio, con el mandato, entre otras cuestiones, de asesorar y prestar asistencia al gobierno en el cumplimiento de su Responsabilidad de Proteger a la población civil.

- La resolución 2014 (2011), de 21 de octubre, del Consejo condena a las autoridades de Yemen por las violaciones de los derechos humanos, recordándose explícitamente al gobierno de este país "la responsabilidad primordial de proteger a su población".

Y en otras cuatro ocasiones, el Consejo ha autorizado incluso el empleo "de todos los medios necesarios" (esto es, también el uso de la fuerza armada) en un contexto de protección de la población civil:

- Así, autorizando la intervención armada de la OTAN en Libia (2011), al amparo de la resolución 1973 (2011), de 17 de marzo, adoptada con la abstención de Rusia y China, miembros permanentes del Consejo.

- La resolución 1975 (2011), de 30 de marzo, citaba "la responsabilidad primordial de cada Estado de proteger a la población civil", autorizándose a la Operación de las Naciones Unidas en Costa de Marfil (UNOCI) a emplear "todos los medios necesarios para proteger la vida y los bienes".

- Y, aunque sin invocarse expresamente (Responsabilidad de Proteger), el Consejo autorizó a la Misión Internacional de Apoyo a la República Centroafricana con Liderazgo Africano (MISCA), con el apoyo de las tropas francesas estacionadas en la zona, a "tomar todas las medidas necesarias" para "la protección de los civiles..., la estabilización del país y el restablecimiento de la autoridad del Estado en todo su territorio", "de conformidad con el concepto de operaciones aprobado el 19 de julio de 2013 y examinado el 10 de octubre de 2013, en su resolución 2127 (2013), de 5 de diciembre ${ }^{35}$. Repárese, igualmente, que la resolución 2149 (2014) que reemplaza la MISCA por MINUSCA bajo responsabilidad directa de Naciones Unidas, autoriza a sus fuerzas a "utilizar todos los medios necesarios"

El Secretario General de Naciones Unidas, por su parte, ha reconocido en su Informe sobre la Responsabilidad de Proteger de 2011 que este concepto ha sido aplicado en los últimos tres años (por tanto 2009, 2010 y 2011), ya para decidir medidas coercitivas armadas o no, "en nuestras estrategias para afrontar las amenazas a la población en unas doce situaciones concretas"; y más en concreto afirma: "Durante los últimos años, el Consejo de Seguridad, yo mismo, mis dos Asesores Especiales [se refiere al Asesor Especial sobre la Prevención del Genocidio y el Asesor sobre la Responsabilidad de Proteger] y otros colegas hemos invocado la responsabilidad de proteger de una forma no coercitiva en Darfur, Kenia, Kirguizistán, Côte d'Ivoire, Yemen, Abyei y Siria. El Consejo de Seguridad solo ha mencionado la responsabilidad de proteger en el caso de la Jamahiriya Árabe Libia en el preámbulo de resoluciones aprobadas en virtud del capítulo VII 1970 (2011 y 1973 (2011)". La función de los mecanismos regionales y subregionales para hacer efectiva la responsabilidad de proteger. Informe del Secretario General, A/65/877-S/2011/393, 28 junio 2011, pp. 1 y 10, párrafos 4 y 30.

35 "Security Council unanimously adopting resolution 2127 (2013), mandate mission in Central African Republic tom protect civilians, restore State authority" (SC/11200, 5 December 2013) http://www.un.org. Párrafo 28 de la resolución. 
para cumplir su mandato (párrafo 29), mandato que implica nada menos que: proteger a los civiles, apoyar la extensión de la autoridad del Estado y la defensa de su integridad territorial, proteger la ayuda humanitaria, proteger al personal y bienes de Naciones Unidas, asegurar la promoción y el respeto de los derechos humanos, ayudar a la justicia nacional e internacional y a mantener el estado de derecho y conseguir el desarme, la desmovilización, la reintegración y la repatriación (párrafo 30, letras a-g).

- Finalmente, la resolución 2140 (2014), de 26 de febrero, sobre el Yemen tras expresar su preocupación por los serios abusos sobre los derechos humanos y violencia ejercida contra la población civil en varias zonas del país, "subraya la necesidad para las partes de tomar todas las medidas necesarias para evitar daños a los civiles y asegurar la protección y el respeto de la población civil" ${ }^{\prime 36}$.

Y nos parece pertinente recordar ${ }^{37}$ que solo el veto de Rusia y China pudo impedir, en el caso de Siria, que el proyecto de resolución votado el 4 de febrero de 2012 en el Consejo ordenara al gobierno sirio a poner "fin inmediatamente a todas las violaciones de los derechos humanos" y a que "proteja a su población". La inaplicación, en su momento, de la Responsabilidad de Proteger en Siria ha sido tan clamorosa al menos como la que se consumó en el conflicto de Darfur, iniciado en el año 2003 sin que en rigor de verdad pueda decirse que haya aún finalizado ${ }^{38}$.

\subsubsection{Ni el deber de prevenir}

Es un hecho generalmente aceptado que el "deber de prevenir", que forma parte del concepto de la Responsabilidad de Proteger, es el primero. La práctica reciente, como los sucesivos Informes del Secretario General sobre la aplicación del concepto desde su aceptación en el año 2005 demuestran, insiste en este punto.

La idea de la prevención de los conflictos y en particular de las crisis humanitarias (del tipo de aquellas a las que la Responsabilidad de Proteger pretende ofrecer una respuesta) no es nueva desde luego, ni por tanto ha nacido con ella. Y, sin embargo, la Responsabilidad de Proteger ha generado, genera, la conciencia de su importancia, de su necesidad, y sirve simultáneamente a los propósitos de crear el clima adecuado y jugar como crisol en el que el impulso y la concreción de medidas de esta naturaleza se convierta en una práctica permanente cada vez que una situación dada suena la alarma de que una crisis de esa naturaleza pueda estar en formación. Sólo por esto (es decir, aunque el concepto encuentre dificultades y resistencias para la aplicación efectiva de todos los elementos que lo integran), la figura de la Responsabilidad de Proteger resulta necesaria en y para la comunidad internacional del tiempo presente.

\footnotetext{
${ }^{36}$ Párrafo 27.

${ }^{37}$ Como, por ejemplo, hace Díaz Barrado, C.M.: “Algunas reflexiones sobre la responsabilidad de proteger”, en Torres Bernárdez, Fernández Rozas, Fernández de Casadevante Romaní y López Martín, op. cit., pp. 739-754, p. 748; o la página web del Programa de Información sobre Genocidio de Rwanda y las Naciones Unidas, en http://www.un.org/preventgenocide/rwanda: "Nota de antecedentes. La responsabilidad de proteger", marzo 2012, pp. 1-4, p. 2.

${ }^{38}$ Sobre una valoración a fondo del conflicto de Darfur y de sus consecuencias desde el punto de vista del Derecho internacional véanse los estudios de Eugenia López-Jacoíste (pp. 23-52), Jiménez Piernas López (pp. 53-94), Rosana Garciandía Garmendia (pp. 95-130), José.Luis Rodríguez-Villasante Prieto (pp. 131-159), María. José Cervell Hortal (pp.161-205), Romualdo. Bermejo García (pp.209-321) y Cesáreo Gutiérrez Espada (pp. 323-414), en Gutiérrez Espada, Cesáreo. (Director) y Cervell Hortal, María José (coord.) (2012): Darfur, el conflicto interminable, Thomson Reuters-Aranzadi, Cizur Menor (Navarra).
} 
Conveniencia y aun necesidad sin duda, y ello a pesar de que es también un hecho que el componente de ese mismo concepto concretado en el "deber de reaccionar" (en particular mediante el uso de la fuerza armada) encuentra notables dificultades en y para su aplicación en la práctica, que tienen que ver, en esencia, con la manifiesta reticencia de muchos Estados en aceptarla y la inequívoca, incluso, hostilidad al mismo que demuestran no pocos de ellos; siendo esto así incluso ante situaciones en las que el "deber de reaccionar" (con la fuerza) resulta aplicable, al darse los presupuestos exigidos. Esta posición, que se alimenta en general de los abusos que en el pasado hayan podido cometerse en el uso de la fuerza pretendidamente con fines humanitarios, se ve en particular robustecida cuando la Responsabilidad de Proteger es objeto de una mala praxis, caso de la aplicación por la OTAN de la autorización concedida para el uso de la fuerza a fin de defender la zona de prohibición de vuelos y la protección de los civiles por el Consejo de Seguridad en su resolución 1973 (2011) en el caso de Libia ${ }^{39}$. Y no obstante, lo cierto es que del mismo modo que el error en la práctica de una determinada técnica para el tratamiento de una enfermedad en un caso dado no debería tener como consecuencia abandonar la técnica en cuestión, si en conjunto parece conveniente, sino más bien preocuparse de evitar los errores en el futuro, lo mismo podría predicarse respecto de la mala praxis de la Responsabilidad de Proteger; o como el propio Secretario General de Naciones Unidas reconoció en el debate general sobre el concepto que tuvo lugar en la Asamblea General en 2012, y ello pese a admitir en el Informe que presentó para ese debate la opinión crítica que la aplicación de la resolución 1973 (2011) generó ${ }^{40}$ :

"el temor de su mal uso tampoco debería inhibir a las naciones a adoptarla frente a graves actos de violencia" ${ }^{41}$.

En cualquier caso queda claro, recuérdese, que la autorización del Consejo de Seguridad sigue siendo, hoy, un elemento condicionante de la legalidad formal de toda intervención armada en el marco del deber de reaccionar que consagra la Responsabilidad de Proteger. También lo está que es el Consejo mismo quien tiene que adoptar esa decisión, sin que exista marco jurídico alguno que regle su adopción.

La parálisis del Consejo animó a intentar, en y para el conflicto en Siria, otras alternativas, que formalmente figuran en las que se han defendido como métodos de la

\footnotetext{
${ }^{39}$ Sobre la mala praxis sugerida véase por ejemplo. ad ex. Bermejo García, Romualdo: "La protección de la población civil en Libia como coartada para derrocar un gobierno: un mal inicio para la responsabilidad de proteger", Anuario Español de Derecho Internacional, no 27 (2011), pp. 9-55; Gutiérrez Espada, Cesáreo.: “Sobre el 'núcleo duro' de la resolución 1973 (2011) del Consejo de Seguridad y acerca de su aplicación en la práctica", Anuario Español de Derecho Internacional, no 27 (2011), pp. 57-75; particularmente claro ha sido Daniel Lagot: "Los países occidentales afirmaron en un principio que no era este su propósito [se refiere a acabar con el régimen del coronel Al-Qhadafi], después que había 'perdido toda legitimidad' y que era preciso pues eliminarle. Lo que ha hecho brillantemente, entre otros lugares en Trípoli y Sirte. El Consejo no ha condenado sus acciones y la ONU ha ratificado todo lo conseguido (incluido el reconocimiento de un nuevo poder libio)" ("Droit international et 'guerres humanitaires", en Andersson Nils y Lagot, Daniel (dir.) (2012): Responsabilité de protéger et guerres "humanitaires”. Le cas de la Libye, L’Harmattan, París, pp. 2-20, 19). Y quizás, por enseñar un botón de muestra significativo, el ataque al convoy en el que Al-Qhadafi huía de Sirte y que fue causa mediata de su muerte, en octubre de 2011, es un buen ejemplo (sobre el mismo véase Gutiérrez Espada C. (2012): La responsabilidad internacional de las organizaciones internacionales en el proyecto definitivo de artículos de la CDI, Comares, Granada, pp. 39-40).

40 "Otros han expresado la opinión de que los encargados de aplicar la resolución 1973 (2011) del Consejo de Seguridad sobrepasaron el mandato que les había otorgado el Consejo" (La responsabilidad de proteger: respuesta oportuna y decisiva. Informe del Secretario General, A/66/874-S/2012/578, 25 julio 2012, cit., p. 17, párrafo 54).

41 "Ban llama a no hacer mal uso de la responsabilidad de proteger", Centro de Noticias ONU, 5 de septiembre 2012, en http://www.un.org.
} 
responsabilidad de prevenir, pero que en el caso sirio llegaban tarde: enviado especial conjunto de Naciones Unidas y la Liga Árabe y un plan de paz ${ }^{42}$.

El Consejo de Seguridad autorizó también el despliegue de la UNSMIS (Misión de Supervisión de Naciones Unidas en Siria) ${ }^{43}$, pero con un mandato muy débil: "observadores (no armados), para contribuir a implementar el plan de paz". Sus actividades, sin embargo, se suspendieron en agosto de 2012 ante la imposibilidad de alcanzar un alto el fuego entre las partes y ninguna otra misión se ha desplegado en la zona.

\subsubsection{Ni el deber de reaccionar}

Y, no obstante, sin el "deber de reaccionar" (en toda su amplitud, incluida en su caso la intervención armada) la Responsabilidad de Proteger pierde su quintaesencia, probablemente su razón de ser última en el contexto de la época que la ha visto nacer.

Más aún, es absurdo la marginación de una opción que puede resultar absolutamente necesaria, como la práctica reciente demuestra: Siria (2011-2014), en el que el solo veto de dos de los miembros permanentes del Consejo, Rusia y China, han impedido su aplicación) (supra párrafo 14 in fine), y que en definitiva supone hacer de la Responsabilidad de Proteger "una poderosa herramienta para abordar este desafío (a la comisión de atrocidades en masa se refiere)" ${ }^{\prime 4}$.

\subsubsection{Ni el deber de castigar}

Castigar a los culpables de los crímenes de guerra y crímenes contra la humanidad perpetrados en Siria es la otra gran cuestión ausente en el conflicto. No en vano, esta es una de las medidas que el Secretario General incluía en el segundo pilar de la Responsabilidad de Proteger $^{45}$. Mientras que la resolución 1970 (2011) sobre Libia permitía la apertura de procedimientos ante la CPI, nada hace pensar, al menos hasta el momento, que podamos llegar a ver órdenes de arresto contra nacionales sirios. Siria no es parte en el Estatuto de la Corte, con lo que la decisión corresponde en única instancia al Consejo de Seguridad, por la vía de reenvío que permite el artículo 13.b del Estatuto y que ya hizo efectiva en los asuntos de Darfur y Libia; de ahí que en el marco de la posición de la Unión Europea, que reclama "no haya impunidad" para las violaciones del Derecho Internacional Humanitario y los graves abusos contra los derechos humanos cometidos en el conflicto sirio ${ }^{46}$, el Parlamento Europeo se haya expressis verbis referido a esta cuestión, reiterando:

\footnotetext{
"su llamamiento de que el Consejo de Seguridad remita el asunto a la CPI para su enjuiciamiento formal",
}

\footnotetext{
${ }^{42}$ Véase el anexo a la resolución 2042 (2012), de 14 de abril.

${ }^{43}$ Resolución 2043 (2012), de 21 de abril. La operación tenía previsto un plazo de de noventa días, que fueron posteriormente ampliados a treinta más.

${ }^{44}$ Llanos Mardones, HugoIgnacio: "La Responsabilidad de Proteger: el rol de la comunidad internacional", Revista Tribuna Internacional, vol. 1, n 2 (2012), pp. 129-139.

${ }^{45}$ En el segundo pilar, recordemos, se reflexiona sobre la obligación de la comunidad internacional de ayudar a los Estados a cumplir con sus obligaciones respecto de la población civil (Informe del Secretario General sobre cómo hacer efectiva la Responsabilidad de Proteger, A/63/677 (2009) cit., párrafo 44). El Secretario General ha recordado en varias ocasiones posteriormente el papel esencial de la CPI en la responsabilidad de proteger (así, en el Informe sobre la función de los mecanismos regionales y subregionales para hacer efectiva la responsabilidad de proteger de 2011, el párrafo 37 señalaba su labor en la prevención y para asegurar la responsabilidad).

${ }^{46}$ Council conclusions on Syria 3241 st. Foreign Affairs Council meeting, Brussels, 27 may 2013 cit.)

${ }^{47}$ Resolución de 12 de septiembre de 2013, párrafo 6, P7_TA [2013]0378).
} 
La resolución 2118 (2013), de 27 de septiembre, del Consejo expresaba la convicción (párrafo 15) de que las "personas responsables del empleo de armas químicas en la República Árabe Siria deben rendir cuentas de sus actos", pero no identificaba de manera clara si el ataque fue efectivamente obra del Gobierno, algo que, por cierto, tampoco aclaró el Informe de 13 de diciembre de la Misión de Expertos de Naciones Unidas que se envió a Siria con tal fin ${ }^{48}$ y de lo que sí está convencido el Parlamento Europeo ${ }^{49}$. La ausencia de la remisión de la cuestión a la CPI fue expresamente lamentada por Australia y Luxemburgo en los debates previos a la aprobación de la resolución, pero incluir la opción resultó imposible por la amenaza del veto ruso. Es más, como Anexo II se incluyen unos "Principios y directrices para una transición en Siria" adoptados el 30 de junio de 2012, que indican claramente que las cuestiones de responsabilidad (artículo 10.2) son parte de la solución política de la crisis. Y es que el convencimiento de algunos de que, en ese momento, depuración de responsabilidades y desarme químico eran incompatibles pues las órdenes de arresto contra miembros del Gobierno supondrían dar por finalizada su colaboración en el proceso, terminó imponiéndose a aquellos que, como Francia, la Alta Comisionada de Derechos Humanos de la ONU, la Comisión de investigación de Siria (en su informe de febrero de 2013) o el Asesor para la Prevención del Genocidio ${ }^{50}$ entendían que ambas opciones eran perfectamente posibles de manera simultánea.

La aprobación de la resolución 2139 (2014) sobre Siria volvía a reabrir el debate del reenvío a la CPI, pero muy tímidamente y sin éxito alguno ${ }^{51}$, pese a que su párrafo 2 afirma que las violaciones del derecho internacional humanitario y los derechos humanos pueden constituir crímenes de guerra y crímenes de lesa humanidad y su párrafo 13 que "quienes han cometido esas violaciones deben comparecer ante la justicia”. ¿Qué justicia? ¿Acaso está la justicia interna en condiciones de empezar a juzgar a los culpables?

No parece posible, sin embargo, ver caer el fruto, por más que el árbol se remueva. Un proyecto de resolución presentado Francia en el que el Consejo de Seguridad:

\begin{abstract}
"Reaffirms its strong condemnation of the widespread violations of human Rights and international humanitarian law by the Syrian authorities and pro-government militias, as well as the human rights abuses and violations of international humanitarian law by nonState armed groups, all committed in the course of the ongoing conflict yn the Syrian Arab Republic since March 2011”,
\end{abstract}

$\mathrm{y}$

"Decides to refer the situation of the Syrian Arab Republic described in the paragraph 1 above since March 2011 to the Prosecutor of the International Criminal Court"

fue vetada el 22 de mayo de 2014 por Rusia y la República Popular China ${ }^{52}$.

2.2.4. Y aún así es, éste, un concepto que debe mantenerse y, por ello, reformarse

Pero, como antes decía, el concepto de Responsabilidad de Proteger sigue siendo necesario. Y si esto es así, resultará preciso introducir en él ciertas reformas. El mismo Secretario General

\footnotetext{
${ }^{48}$ Doc. A/68/663-S/2013/735. Para el texto del Informe, infra nota 97.

${ }^{49}$ Véase nota 121.

${ }^{50}$ Declaración de 20 de diciembre de 2012 (UN News Centre).

${ }^{51}$ Algunos Estados volvieron a defender en los debates de la resolución el papel de la CPI :Australia (p. 4), Chile (p. 12) y Lituania (p. 14).

${ }^{52}$ El texto del proyecto vetado, así como una valoración tanto del mismo como de los argumentos de quienes votaron a favor y en contra en el Consejo de Seguridad en Weckel, Ph.: "La Russie et la Chine ne veulent pas de la justice en Syrie", Sentinelle, n 393, 25 de mayo de 2014, pp. 1-24, en http://www.sentinelle-droitinternational.fr.
} 
parece reconocerlo implícitamente en su Informe de 2011 sobre la aplicación de la Responsabilidad de Proteger ${ }^{53}$. Reformas, en particular, que le doten de un efecto útil, del que carece con una situación como la actual condicionada por el derecho de veto tal y cual éste se conforma. La necesidad de estas reformas deriva directamente del hecho de la consideración como intereses de la comunidad internacional en su conjunto protegidos por normas imperativas de aquellos a los que la Responsabilidad de Proteger busca salvaguardar. Y la realidad de la protección normativa asignada a dichos intereses, unida a su importancia y rango, exige a nuestro juicio insistir en la idea de que la Responsabilidad de Proteger debe actuar siempre y cada vez que aparezca la vulneración de esos intereses, aparezca donde aparezca; no se debería en consecuencia seguir dejando en manos del Consejo de Seguridad la posibilidad (como hoy ocurre) de actuar o no de acuerdo con circunstancias políticas o geoestratégicas que tampoco se concretan.

Esas reformas incluiría la adopción por el Consejo de Seguridad de una resolución que incluyese los principios básicos necesarios para autorizar un uso de la fuerza armada por razones de humanidad ${ }^{54}$; porque en la actual situación no existe, nos parece, medio jurídico alguno de forzar al Consejo a adoptar medidas en casos en los la Responsabilidad de Proteger es aplicable. Pero esto no sería suficiente.

Las reformas deberían alcanzar el derecho de veto en el Consejo de Seguridad. Con la posibilidad de utilizar el derecho de veto tal y como hoy existe, que permitiría impedir la aplicación del concepto a supuestos en los que la Responsabilidad de Proteger es aplicable, se priva a esta figura de efecto útil, quitándose con una mano (el veto tal cual está) lo que se ha dado con la otra (la comunidad internacional debe impedir las atrocidades) ${ }^{55}$. Siendo el objetivo final su eliminación, el proceso pasaría probablemente, como se ha sugerido en una reciente propuesta de reforma de la $\mathrm{Carta}^{56}$, por su gradual eliminación por fases a lo largo de un período de, aproximadamente, quince años, que comenzaría por incrementar el número de miembros permanentes necesarios para desencadenar el veto y, simultáneamente, limitando los ámbitos materiales en los que éste pudiera interponerse, empezando por su proscripción en resoluciones que intentar resolver violaciones masivas de los derechos humanos, especialmente genocidio y limpieza étnica ${ }^{57}$.

Reformas, en fin, que deberían llevar a la creación de lo que James Pattison llama una "sólida Fuerza de Naciones Unidas cosmopolita" decidida en un contexto de "instituciones democráticas cosmopolitas", que sería la encargada de llevar a cabo las intervenciones armadas por causa de humanidad ${ }^{58}$.

\footnotetext{
53 "Todavía no se ha elaborado bien la doctrina para el uso de recursos militares y de mantenimiento de la paz en el contexto de la prevención y la disuasión de atrocidades o la respuesta a ellas" (La función de los mecanismos regionales y subregionales para hacer efectiva la responsabilidad de proteger. Informe del Secretario General, A/65/877-S/2011/393, 28 junio 2011 cit., p. 12, párrafo 35).

${ }^{54}$ Véase López-Jacoiste Díaz, Eugenia (2012): "Repensando el sistema de seguridad colectiva: el Consejo de Seguridad y las nuevas amenazas la paz y seguridad internacionales”, en C. Ramón Chornet (coord.): La acción colectiva del uso de la fuerza. Nuevos escenarios, "nuevos" principios de actuación en el orden internacional, Tirant lo Blanch, Valencia, pp. 61-144, 131-137.

${ }^{55}$ Sin que se refleje expressis verbis, la idea de que sin una reforma del derecho de veto el concepto de la Responsabilidad de Proteger se vería privado de su capacidad de aportación a un Derecho internacional y unas Relaciones internacionales más justas, está presente en Palacián de Inza, B.: "La responsabilidad de proteger y el derecho de veto”, Documento de Análisis 09/2012 (15 de febrero de 2012), pp. 1-8, en www.iee.es.

${ }^{56}$ Schwartzberg, J.E. (2013): Transforming the United Nations System. Or a Workable World, United Nations University Press, Tokyo-Nueva York-París (en particular pp. 89-90).

${ }^{57}$ Blätter, Ariela.: "The Responsability Not to Veto: A Way forward”, pp. 1-12, Cityzens for Global Solution 2010, en http://www.globalsolutions.org; Schwartzberg, op. cit., p. 90.

58 "Humanitarian Intervention and Responsability to Protect", op. cit., pp. 233-236 (y más en general, pp. 219243).
} 
Parece claro que estas reformas, por convenientes que resulten, no cuentan con posibilidades serias de éxito en un futuro predecible.

La vía más sencilla, práctica y rápida posible para reformar el sistema vigente de la Responsabilidad de Proteger (con ciertos ajustes, sí) es la que ha propuesto formalmente Francia sobre el derecho de veto en Naciones Unidas (septiembre 2013). Permíteme, tú que me lees, que haga, en el párrafo siguiente, una reflexión crítica sobre la misma.

A finales de 2013, Francia planteaba formalmente una propuesta sobre el derecho de veto. El 24 de septiembre de 2013, en su intervención en el debate de apertura del $68^{\text {a }}$ período de sesiones de la Asamblea general, el Presidente de la República de Francia, François Hollande, propone en términos muy escuetos y en el contexto de su referencia al alcance de la inacción de Naciones Unidas en los ámbitos de la seguridad internacional, la proliferación nuclear, el desarrollo o el clima, la adopción:

"de un código de buena conducta (...) entre los miembros permanentes del Consejo de Seguridad y que en el caso de los crímenes masivos, ellos puedan renunciar colectivamente a su derecho de veto" ${ }^{, 59}$.

Unos días después, el 4 de octubre, Laurent Fabius, Ministro de AAEE de Francia, publica un artículo en Le Monde en el que se contienen concreciones relevantes sobre esta propuesta: de un lado, aclara algo que, implícito acaso en la sencilla propuesta del Presidente de Francia (al referirse a un "código de conducta"), conviene en todo caso saber expresamente: "este proceso se llevaría a cabo sin modificar la Carta"; de otro, precisa los criterios de aplicación de la misma; y, finalmente, el Ministro de AAEE apunta lo que, en su parquedad, no podía adivinarse en la propuesta del Presidente Hollande: este código de conducta excluiría los casos en los que un miembro permanente del Consejo considerase que sus intereses vitales nacionales se ponen en peligro ${ }^{60}$.

El representante permanente adjunto de Francia ante Naciones Unidas por último, en su intervención de 7 de noviembre de 2013, nos aclara, por si había alguna duda, que la propuesta francesa está abierta a otros posibles acuerdos finales, sin que la idea concreta sugerida por su país deba tomarse como una decisión cerrada. Y ello es así tanto en cuanto a la consideración de qué sea un crimen masivo como respecto de las modalidades prácticas en general que permitan la aplicación del código de conducta propuesto. En definitiva, Francia pide a los miembros permanentes del Consejo de Seguridad que se pongan de acuerdo sobre estos extremos, indicando en particular el representante galo, con referencia al concepto de crimen masivo, que

"la declaración de la cumbre mundial de 2005 y numerosos tratados internacionales, entre ellos la convención de 1948 sobre el genocidio o incluso el Estatuto de Roma pueden guiarnos" $"$.

\footnotetext{
59 “AGNU: Discours du Président Francois Hollande. Débat d'ouverture de la 68eme session de l'Assemblée Générale. Intervention de M. Francois Hollande, Président de la République", en www.fr.ambafranceus.org/spip.php?article4926, pp. 1-3.

60 "Suspender el derecho al veto en los casos de crímenes masivos. Tribuna de Laurent Fabius", 4 de octubre de 2013", pp. 1-2, en www.diplomatie.gouvfr/es.

61 "Nations Unies- Réforme du Conseil de Sécurité"- Intervention du représentant permanente adjoiont de la France auprès des Nations Unies, New York 7 de noviembre de 2013", en Weckel, Ph.: "Conseil de Sécurité, le nécessaire débat sur la limitation du droit de véto des membres permanents", Bulletin Sentinelle, no 365 (10 de noviembre de 2013), pp. 1-3, en www.sentinelle-droit-international.fr.
} 
La propuesta francesa se efectúa en un contexto en el que la figura de la Responsabilidad de Proteger aparece claramente subyacente, dado que se enmarca con referencia clara y directa con el conflicto armado interno que viene desarrollándose en Siria desde el primer trimestre de 2011 y la gravísima crisis humanitaria que en ese país se vive desde entonces. El discurso del Presidente francés, Hollande, ante la Asamblea General de Naciones Unidas lo dejó muy claro $^{62}$.

Varios meses después (marzo 2014), el Sr. Araud, Representante Permanente de Francia ante Naciones Unidas, confirmaba esta misma conexión en la entrevista a la cadena France 24. La propuesta francesa, afirmó Gérard Araud:

"se inspira evidentemente en lo que acaba de ocurrir en Siria cuando hemos visto a Rusia interponer por tres veces su veto en un caso en el que sin duda posible se habian cometido atrocidades en masa, dado que se contabilizan ya 150.000 muertos en la guerra civil ${ }^{, 63}$.

El Código de Conducta sugerido por Francia plantea una autolimitación, por parte de los miembros permanentes del Consejo de Seguridad, de su derecho de veto, en ciertos supuestos excepcionales (cuya precisión se intenta objetivar mediante un procedimiento determinado), pero con la existencia, sí, de una cláusula de salvaguardia. Tres elementos, pues, caracterizan su contenido:

A) Los miembros permanentes del Consejo, propone Francia, renunciarán al derecho de veto que la Carta les reconoce cuando se den hechos de particular gravedad. Repárese, entonces, en que el acuerdo al que llevaría la propuesta gala es, en realidad, un texto político, que genera para sus autores obligaciones morales o políticas, no un compromiso exigible en términos jurídicos ${ }^{64}$.

Repárese también en que la propuesta francesa sugiere un acuerdo en este sentido de los miembros permanentes del Consejo de Seguridad previo al planteamiento de un caso y que, de darse éste y prosperar el mecanismo de aplicación y determinación del mismo previsto en la propuesta, la renuncia del derecho de veto jugaría automáticamente; las precisiones que de la sucinta propuesta del Presidente de la República ante la Asamblea General de Naciones

${ }^{62}$ Si la omega de sus palabras fueron:

"es responsabilidad de Naciones Unidas actuar. Y cada vez que nuestra organización se muestra impotente, es la paz la que primero sufre. Propongo yo por ello que un código de buena conducta pueda ser definido entre los miembros permanentes del Consejo de Seguridad y que en el caso de crímenes en masa puedan decidir renunciar colectivamente a su derecho de veto";

la letra alfa de las mismas hablaron de Siria:

"Siria urge. Y urge porque 120.000 personas han muerto en dos años y medio y 90.000 sólo en el último. Un cuarto de la población ha debido desplazarse fuera del Estado. Son millones los sirios que buscan refugio fuera de su país. Siria está destruida" (“AGNU: Discours du Président François Hollande...” cit., pp. 3 y 1 respectivamente).

63 "Document 31 mars 2014. Suspension du droit de véto en cas de crimes de masse. Entretien de M- Gérard Araud, representante permanente de France auprès des Nations Unies, avec France 24", texto que reproduce parcial pero íntegramente la entrevista en Weckel, Ph.: "Conseil de Sécurité: Pousuite du projet de suspensión du droit de véto face aux crimes de masse", Sentinelle, no 386, 6 de abril de 2014, pp. 1-4, en http://www.sentinelledroit-international.fr.

${ }^{64}$ En palabras del tunecino Habib Slim, se trata de un "gentlemen's agreement" que adopta une "especie de código moral que vendría a completar la Carta": "A propos de la récente proposition française de réforme du droit de véto au Conseil de Sécurtité”, Sentinelle, n 362, 20 de octubre de 2013, pp. 1-6. 
Unidas (septiembre 2013) realizara (en octubre) su Ministro de AAEE lo dejan perfectamente claro:

"Una vez que el Secretario General haya dado su dictamen, se aplicaría el código de conducta inmediatamente" 65 .

B) La autolimitación del veto por los miembros permanentes del Consejo de Seguridad tendría lugar en el caso de la comisión de crímenes masivos. Naturalmente, resultará necesario, en tal caso, llegar a un acuerdo sobre este término; ¿a partir de qué número de víctimas, por ejemplo, nos hallamos ante un crimen de esta naturaleza? Ya hemos apuntado que Francia, que hace una sugerencia concreta con un criterio de aplicación de su propuesta "sencillo", no parece considerar su sugerencia innegociable: el representante permanente adjunto de este país dejó abierta, en su intervención ante el Consejo de Seguridad, la decisión en este concreto asunto, remitiéndose al acuerdo entre los miembros permanentes del Consejo y citando algunos textos internacionales que podrían ser de interés con este propósito; y el 31 de marzo de 2014 el mismo representante permanente galo revela los contactos que su país viene manteniendo con otros Estados (vga. los "Cinco Pequeños" a los que nos referiremos enseguida) y con la sociedad civil para "conseguir algo que tenga sentido práctico"66.

Francia propone que la decisión de cuándo se comete un crimen masivo debe dejarse en manos de una autoridad al margen del propio Consejo de Seguridad y, desde luego, de sus miembros permanentes. Y cree que esa autoridad debería ser el Secretario General de Naciones Unidas, al amparo del artículo 99 de la Carta de esta Organización (que autoriza a éste a "llamar la atención del Consejo de Seguridad" respecto de cualquier tema que, "en su opinión", sea susceptible "de poner en peligro el mantenimiento de la paz y la seguridad internacionales"); no obstante, éste no podría, por decirlo así, actuar de oficio, sino a instancias de 50 Estados miembros de Naciones Unidas. En marzo de 2014, el representante permanente galo ante Naciones Unidas sugiere incluso que aunque el Secretario General podría ser la autoridad que desencadenase la puesta en marcha del Código de Conducta, la determinación de si se ha cometido o no un "crimen masivo" puede ser de otros (y pone como ejemplos a la Asamblea General de Naciones Unidas, la CIJ o el Consejo de Derecho Humanos $)^{67}$.

C) La propuesta de Francia incluye, sin embargo, una cláusula de salvaguardia de no poca importancia y alcance, que se justifica con una apelación al "realismo", el compromiso en este tema al que llegarían los miembros permanentes del Consejo:

"excluiría los casos en que los intereses vitales nacionales de un miembro permanente
del Consejo corriesen peligro" 68 .

La propuesta francesa, obsérvese por último, apunta a una reforma "informal" del derecho de veto, en la medida en que su adopción por los miembros permanentes del Consejo no exigiría la enmienda formal de la Carta, con todo lo que ello supondría ${ }^{69}$.

\footnotetext{
${ }^{65}$ Fabius, Laurent.: "Suspender el derecho de veto...", op. cit., p. 1.

${ }^{66}$ Entrevista citada, loc. cit (nota 63), p. 2.

${ }^{67}$ Ibid., p. 2.

${ }^{68}$ Fabius, Laurent.: "Suspender el derecho de veto...", op. cit., p. 1.

${ }^{69}$ En su intervención de 7 de noviembre de 2013 el representante permanente adjunto de Francia creyó oportuno explicitarlo, el código de conducta sugerido, "no implicaría, pues, una reforma del Consejo de Seguridad de Naciones Unidas" ("Nations Unies- Réforme du Conseil de Sécurité- Intervention du représentant permanente...", op. cit., p. 2).
} 
Esta propuesta, como el propio Presidente francés comentara, en una rueda de prensa posterior a su discurso ante la Asamblea General, "no es nueva, ya que su país la formuló por primera vez en 2005 " 70 . Pero también antes se había invocado:

- En el año 2001, el Informe de la CIISE (2001), recuérdese, dice textualmente lo que sigue:

"La Comisión apoya la propuesta sugerida a título exploratorio por un alto representante de uno de los cinco miembros permanentes de que estos deberían acordar un 'código de conducta' sobre la utilización del derecho de veto cuando es preciso actuar para atajar o evitar una importante crisis humanitaria. Básicamente la idea es que los miembros permanentes, cuando sus intereses vitales no se vean comprometidos en un asunto, no harán uso de su derecho de veto para obstaculizar la aprobación de una resolución respaldada por la mayoría (...). Es poco realista pensar que en un futuro próximo podrán enmendarse las disposiciones de la Carta relativas al derecho de veto y su distribución, pero sería conveniente que los miembros permanentes establecieran de mutuo acuerdo una práctica de carácter más oficial que permitiera regular en el futuro las situaciones de este tipo" $"$.

Aunque la Comisión no menciona eo nomine, en su Informe, al miembro permanente del Consejo cuyo alto representante sugirió esta auto-limitación del derecho de veto por acuerdo entre los Estados titulares del mismo en el Consejo de Seguridad, el lector coincidirá conmigo en que, a la luz de la propuesta que hace Francia en el 2013 en Naciones Unidas (incluida la cláusula de salvaguardia de los intereses vitales), todo apunta a que se trataba de este país.

- Asimismo, el Grupo de Alto Nivel afirma en su Informe (2004):

"No vemos forma práctica alguna de cambiar el veto que tienen algunos miembros. Sin embargo, en general la institución del veto (...) no es adecuada (...) en una era de democracia cada vez mayor e instaríamos a que únicamente se utilizara en cuestiones en que realmente estuvieran en juego intereses vitales. Pedimos también a los miembros permanentes que, a título individual, se comprometan a abstenerse de utilizar el veto en casos de genocidio y abusos en gran escala de los derechos humanos",72.

El Informe que el Secretario General presenta (2005) a la Cumbre del Milenio, inspirándose en parte en el presentado por el Grupo de Alto Nivel, pide que el Consejo de Seguridad autorice el uso de la fuerza armada de ser necesario, incluso preventivamente, para evitar la comisión de un genocidio, limpieza étnica, crímenes de guerra o de lesa humanidad o violación masiva de los derechos humanos, solicitando incluso del Consejo que apruebe una resolución en la que se indiquen los criterios que el Consejo debería tener en cuenta a la hora de autorizar una intervención armada por causa de humanidad y en la que se comprometa a aplicarla. El Secretario General, en definitiva, asume el concepto de Responsabilidad de

\footnotetext{
70,24 de septiembre de 2013, p. 1, en http://www.notisistema.com.

71 "La responsabilidad de proteger", Informe de la CIISEs, p. 46 (párrafo 6.21), Carta de fecha 26 de julio de 2002 dirigida al Secretario General por el Representante Permanente del Canadá ante las Naciones Unidas, A/57/303, 14 de agosto de 2002 (El documento A/57/303 recoge como Anexo La responsabilidad de proteger. Informe de la Comisión Internacional sobre Intervención y Soberanía de los Estados, 2 de diciembre de 2001, pp. i-xiii y 1-75)

72 "Informe del Grupo de Alto Nivel sobre las amenazas, los desafíos y el cambio, Un mundo más seguro: la responsabilidad que compartimos", 2 de diciembre de 2004 (A/59/565), p. 77 (párrafo 256).
} 
Proteger que acuñara la CIISE, pero no propone en él limitación alguna del derecho de veto de los miembros permanentes del Consejo ${ }^{73}$. Otro Secretario General, el actual, Ban Ki Moon sí lo ha hecho (2009), ha pedido a los miembros permanentes del Consejo que no utilicen su derecho de veto en estos temas ${ }^{74}$; no le han respondido siquiera o, dicho mejor, el silencio de los miembros permanentes ha sido su respuesta.

El Documento Final aprobado por los Jefes de Estado o de Gobierno de los miembros de Naciones Unidas acepta el concepto de Responsabilidad de Proteger, pero es sumamente ambiguo en cuanto a la reforma del Consejo y de sus métodos de adopción de decisiones en esta cuestión, siendo, en concreto imposible encontrar referencia alguna a una eventual limitación o auto-limitación del derecho de veto de sus miembros permanentes ${ }^{75}$.

- En el proceso de seguimiento de los resultados de la Cumbre del Milenio, Costa Rica, Jordania, Liechtenstein, Singapur y Suiza, los "Cinco Pequeños" (Small-Five o S-5), presentan ante la Asamblea General un proyecto de resolución sobre Mejora de los métodos de trabajo del Consejo de Seguridad, en la que piden que

"Ningún miembro permanente debería emitir un voto discrepante en el sentido del párrafo 3 del artículo 27 de la Carta en caso de genocidio, crímenes de lesa humanidad, y graves violaciones del derecho internacional humanitario" ${ }^{, 76}$.

La reforma del Consejo de Seguridad, y compris sus métodos de adopción de decisiones, sigue estando de actualidad, en particular cuando se conecta con la aplicación de la Responsabilidad de Proteger:

- El martes, 2 de mayo de 2013, un nuevo grupo, el grupo ACT (Accountability, Coherente, and Transparence), formado por 21 Estados y coordinado por Suiza ${ }^{77}$, declaró su propósito de continuar el esfuerzo que durante años llevaron a cabo los "Cinco Pequeños" (S-5) en la mejora de los procedimientos de adopción de decisiones del Consejo de Seguridad. En particular, insistiendo en su proyecto de resolución de mayo de $2012^{78}$, recuérdese, con la guerra de Siria, que aun hoy prosigue, en su apogeo, que fue retirado a causa de las intensas presiones de los cinco miembros permanentes del Consejo ${ }^{79} \mathrm{y}$, más en

\footnotetext{
73 "Informe del Secretario General, Un concepto más amplio de la libertad: desarrollo, seguridad y derechos humanos para todos", 21 de marzo de 2005 (A/59/2005), pp. 64-65 (párrafos 6 y 7).

${ }^{74}$ Un diplomático chileno, que participó en la negociación del Documento Fin al (2005), entiende que al hacerlo así el Secretario General "llenó este vacío" (Llanos Mardones, H.I.: "La Responsabilidad de Proteger: el rol de la comunidad internacional" cit., p. 139). En efecto, en su primer Informe (2009) sobre la aplicación de la Responsabilidad de Proteger el Sr. Ban Ki Moon lo hizo: "Los cinco miembros permanentes del Consejo de Seguridad tienen una responsabilidad especial debido a los privilegios de titularidad y derecho de veto que les han sido concedidos en la Carta. Les instaría a abstenerse de ejercer o amenazar con ejercer su derecho de veto en situaciones en que sea evidente que no se han cumplido obligaciones relativas a la responsabilidad de proteger, como se describe en el párrafo 139 [se refiere al del Documento Final de la Cumbre de 2005], y a alcanzar un entendimiento mutuo con ese fin" ("Hacer efectiva la responsabilidad de proteger...", op. cit., pp. 2930, párrafo 61.

75 "Documento Final de la Cumbre Mundial...", op. cit., p. 38 (párrafos 138 y 139).

76 A/60/L.49, 17 de marzo de 2006, Anexo: medidas sobre los métodos de trabajo propuestas al Consejo de Seguridad para que las examine, párrafo 14.

77 Arabia Saudí, Austria, Costa Rica, Chile, Eslovenia, Estonia, Finlandia, Gabón, Hungría, Irlanda, Jordania, Liechtenstein, Nueva Zelanda, Noruega, Papua Nueva Guinea, Perú, Portugal, Suecia, Suiza, Tanzania [obs.] y Uruguay.

${ }^{78}$ Doc. A/66/L.42/Rev. 2

${ }^{79}$ Véase Deen, Thalif.: "Los 'cinco grandes' de la ONU aplastan cuestionamiento de naciones", p. 4, www.voltairenet.org/article174657.html.
} 
concreto, prosiguiendo su lucha para conseguir la adopción del párrafo 20 de su proyecto L.42 que reclamaba de los miembros permanentes del Consejo que se abstuvieran de usar su derecho de veto para bloquear una acción del Consejo destinada a evitar o poner fin a un genocidio, crímenes contra la humanidad o crímenes de guerra a gran escala ${ }^{80} \mathrm{o}$, al menos, del párrafo 19 que instaba en un documento aparte que sería distribuido a todos los miembros, a explicar las razones por las que se había optado por ejercer ese veto, en particular su conformidad con la Carta de Naciones Unidas.

- Finalmente, y en el marco de su examen anual del Informe del Consejo de Seguridad (1 de agosto de 2012-31 de julio de 2013), la Asamblea General ha criticado el funcionamiento del Consejo y sus métodos de trabajo. Merece la pena destacar las intervenciones de tres de las delegaciones que hicieron uso de la palabra: Alemania, considerando que la propuesta de Francia, presentada por el Presidente Hollande, merecía ser estudiada por el Consejo más adelante; Hungría que se unió a esa reflexión y critica además el silencio que sobre la misma se guarda en el Informe del Consejo de Seguridad; y, finalmente, Maldivas que expresó su inequívoco apoyo a la propuesta gala ${ }^{81}$.

La propuesta francesa es en conjunto positiva y la iniciativa digna de elogio. Su sencillez, que no fuerza a una enmienda formal de la Carta, como el representante permanente de Francia dejó claro, es un atractivo indudable pues salvaría los formidables obstáculos que un proceso de esa naturaleza implicaría. Debe destacarse también el esfuerzo de Francia por intentar objetivar en todo lo posible la aplicación de su propuesta. De ahí, esa fórmula, política y jurídica, que pretende que la determinación de cuando nos encontramos ante un "crimen de masas" y por ende susceptible de desencadenar de manera automática la suspensión del derecho de veto, abra un proceso en el que, a instancia de un número relevante de Estados miembros de la Asamblea General (50 en este caso), sea un "tercero" imparcial quien se pronuncie. La elección del Secretario General de Naciones Unidas, al amparo de sus competencias ex artículo 99 de la Carta, uno de los órganos principales de la Organización, no priva a la fórmula de alcance jurídico pero sí la tiñe también de política; posiblemente para facilitar su aceptación .

Tiene, no obstante, la propuesta gala su talón de Aquiles. No es aceptable que la aplicación de ese Código de Conducta que Francia propone de nuevo con oportunidad y acierto quede a expensas de la cláusula de salvaguardia que se defiende. Si permitimos a uno de los miembros permanentes del Consejo poder evitar ese Código alegando la existencia de un interés vital nacional, estamos quitando con una mano lo que hemos dado con la otra. Se ha sugerido doctrinalmente que acaso la CIJ podría, llegado el caso, ser consultada a los efectos de definir en términos objetivos la figura del "interés vital nacional", limitando su invocación a algunas situaciones "extremas de legítima defensa" en los que "la supervivencia misma del Estado estuviera en peligro"82. Difícil de aceptar por los Estados este control judicial de un concepto tan rabiosamente político y metajurídico; acaso la exigencia de que la determinación de la existencia en el caso de un interés vital nacional de uno de los miembros permanentes fuese asumida y reconocida por uno o, mejor, dos más de ellos, sería una

\footnotetext{
${ }^{80}$ Pace, William.: "21 member Status launch new initiative to improve the working methods of the Security Council", 12 de mayo de 2013, pp. 1-10, en www.centerforunreform.org/node/500.

${ }^{81}$ Véase Brusil Miranda, Metou.: L' Assemblée générale critique les méthodes de travail et le fonctionnement du Conseil de Sécurité", Sentinelle, $\mathrm{n}^{\circ}$ 368, 1 de diciembre de 2013, pp. 5-7, http://www.sentinelle-droitinternational.fr.

$\overline{82}$ Términos, se recordará, empleados por la misma Corte en su dictamen consultivo de 8 de julio de 1996 en el asunto sobre la "ilicitud de la amenaza o el empleo de las armas nucleares", Opinión Consultiva de 8 de julio de 1996, ICJ Reports 1996, p. 226, 263 (párrafos 96-97). Slim, op. cit., pp. 3-4.
} 
fórmula política desde luego pero que intentaría una mayor objetivización en la puesta en marcha de la cláusula de salvaguardia. En todo caso, el deber ser aconsejaría prescindir sin más de la misma.

No cabe ser demasiado optimistas sobre esta propuesta, tan útil como oportuna. Ni aún con la cláusula de salvaguardia comentada (que personalmente eliminaría), los otros miembros permanentes del Consejo parecen proclives a debatir el tema, cuanto más a aceptar lo que se propone. Un botón de muestra bastará: el martes, 5 de febrero de 2013, el viceministro de asuntos exteriores de Rusia, Gennady Gatilov, declaraba a la prensa rusa, tras el encuentro ministerial celebrado en Roma por iniciativa de España e Italia con el objetivo de debatir la reforma del Consejo de Seguridad, sus métodos de trabajo y procesos de toma de decisiones, que su país estaba dispuesto a aceptar cualquier propuesta de reforma, en cuanto a la composición del Consejo, que contase con un respaldo mayoritario ${ }^{83}$; pero, en relación con los métodos de adopción de decisiones del Consejo, el viceministro ruso fue menos conciliador $^{84}$. La negativa posición rusa a la propuesta francesa ha sido confirmada, el 31 de marzo de 2014, por el representante permanente antes las Naciones Unidas de ese país en la entrevista concedida a France 24. El Sr. Araud concretó asimismo en ella que en esta línea se mueve también la República Popular China, mientras que los Estados Unidos mantienen una cautelosa actitud; sólo el Reino Unido de Gran Bretaña e Irlanda del Norte ha mostrado su interés por el Código de Conducta propuesto por su país, afirmó. No descartó el Sr. Araud la firma del mismo solo por tres de los cinco miembros permanentes (Francia, Reino Unido y los Estados Unidos) ${ }^{85}$.

Así las cosas, la Responsabilidad de Proteger lleva, en su estado actual, a dos conclusiones fundamentales:

A) La primera, nos recuerda que este concepto no es ya, per se, una excepción jurídicamente admitida a la prohibición del uso de la fuerza armada en las Relaciones internacionales contemporáneas. Su "legalidad", en cuanto a su manifestación armada se refiere, está condicionada por el derecho de veto en el Consejo de Seguridad.

Desde esta perspectiva, parecen ajustarse a la realidad de las cosas quienes consideran que en rigor el concepto de la Responsabilidad de Proteger sólo:

"refleja una evolución en el modo como el Consejo de Seguridad evalúa o considera sus poderes según los artículos 39 a 42 de la Carta" ${ }^{\text {, }}$.

Esto es, parece querer decirse, que dicho concepto justificaría per se la imposición por el Consejo de medidas coercitivas, incluidas las que implican el uso de la fuerza militar, más allá

\footnotetext{
83 "Rusia mantiene una postura flexible y pragmática al respecto (...) estamos dispuestos a considerar tanto la opción que presupone un aumento del número de miembros permanentes y no permanentes, como el modelo denominado ‘intermedio' que supondría únicamente un aumento de los miembros no permanentes".

${ }^{84}$ Sin referirse expresamente al tema en concreto, sí dejo clara la posición de Rusia sobre propuestas como las que sugieren una auto-limitación permanente respecto de ciertas cuestiones del derecho de veto:

"La imposición de unos límites provisionales para la toma de decisiones, sin embargo, es inadmisible, ya que se trata de una cuestión delicada cuya solución podría dar lugar a una disgregación de países en lugar de mejorar la eficacia del Consejo de Seguridad, con las evidentes consecuencias negativas que esto supondría" ("Rusia apoya una reformas del Consejo de Seguridad de la ONU", 7 de febrero de 2013, pp. 1-2, en www.rusiahoy.com,).

${ }^{85}$ Este hecho, comentó Gérard Araud, ejercería posiblemente:"una presión moral muy fuerte sobre Rusia o China en los casos de comisión de atrocidades en masa"Entrevista citada, loc. cit., pp. 2 y 3.

${ }^{86}$ Caso del profesor James Crawford (2012): Brownlie's Principles of Public International Law, Oxford University Press, Oxford ( $8^{\mathrm{a}}$ ed.), p. 756.
} 
de la exigencia de una previa y preceptiva declaración formal, ex artículo 39 de la Carta, de que se ha producido "una amenaza o ruptura de la paz" (sin que, por lo demás, repárese, exista regla alguna que le obligara a hacerlo). Salvo, como el IDI ha sugerido en su resolución de Rodas (2011) sobre La autorización del recurso a la fuerza por Naciones Unidas (artículo 6), que el Consejo asuma el criterio y lo ponga en práctica de que la existencia de un genocidio, limpieza étnica, o crímenes masivos de guerra o contra la humanidad son necesaria, siempre y sustancialmente una amenaza a la paz y seguridad internacionales.

B) La segunda nos lleva a pensar sobre cual sería la calificación jurídica de las intervenciones armadas por causa de humanidad realizadas sin la autorización del Consejo de Seguridad. La respuesta natural y más fácil, considerarlas contrarias al Derecho internacional sin más, parece demasiado fácil, sencillamente porque estaría ignorando el carácter jurídico, y del máximo rango, que hoy tiene la prohibición del genocidio, la depuración étnica, los crímenes de guerra o contra la humanidad a gran escala.

Naturalmente, y dada esa premisa, una resolución de la Asamblea general, en aplicación de la resolución 377 A (V) ("Unión pro Paz"), de 3 de noviembre de 1950, sería, en casos de bloqueo del Consejo, una cobertura jurídica legítima para las intervenciones armadas por causa de humanidad en el marco de la Responsabilidad de Proteger. Tres recordatorios: uno, así lo pensaba la CIISE (2001); dos, el mismo Secretario General de Naciones Unidas, en el año 2009, ha visto en la Asamblea General, de conformidad con la resolución 377 (V), un órgano legitimado para recomendar en este contexto medidas coercitivas con base en el artículo 41 de la Carta $^{87}$; y tres, así lo propone expresamente el IDI en su resolución de Rodas (2011) (artículo 7). Item más: no resulta superfluo recordar, aquí y ahora, que la CIJ ha aplicado sin plantearse problema alguno de su incompatibilidad con la Carta, la resolución 377 A (V) en el asunto sobre las consecuencias de la edificación de un muro en territorio palestino (ocupado) (2004), entendiendo que la resolución por la que la Asamblea General, en un período extraordinario de sesiones de emergencia, pidió su dictamen en este caso se ajustaba a los requisitos exigidos por la resolución 377 A (V) para poner en marcha el procedimiento por ella previsto y que en éste, como hizo la Asamblea, era perfectamente legítima plantear una resolución demandando de la Corte un dictamen consultivo sobre el asunto $^{88}$.

Y fuera de estos casos, la intervención armada por causa de humanidad que una coalición de Estados o una Organización regional, sin autorización del Consejo, bloqueado este por el ejercicio del derecho de veto, no debería considerarse ilegal si cumple con todos los requisitos exigidos por la doctrina de la Responsabilidad de Proteger, muy en particular, desde luego, si el propio Consejo la avalase a posteriori.

\footnotetext{
${ }^{87}$ El Sr. Ban Ki Moon se refiere en concreto a medidas coercitivas no armadas (artículo 41 de la Carta), pero, aceptado esto, no vemos razón, desde la línea de argumentación del SG, para excluir esa posibilidad en el caso de medidas coercitivas armadas (artículo 42) si se precisaran ("La Asamblea General también puede considerar la posibilidad de adoptar sanciones de conformidad con la resolución 377 V], titulada 'Unión pro Paz', aunque éstas no tendrían fuerza jurídica obligatoria”, Hacer efectiva la responsabilidad de proteger. Informe del SG, A/63/677, 12 enero 2009, p.28, párrafo 57).

${ }^{88}$ Opinión consultiva de la CIJ sobre las consecuencias de la edificación de un muro en el territorio palestino ocupado, 9 de julio de 2004, ICJ Reports 2004, p. 136, párrafos 29-32 (citamos el texto íntegro en español de la Opinión consultiva, que sigue a la Nota explicativa del Secretario General, del documento A/ES-10/273, distribuido oficialmente el 13 de julio de 2004).
} 
Pero no deseo poner fin a este apartado que a la postre propone no condenar a la ilegalidad eventuales intervenciones humanitarias que se llevan a cabo de modo ortodoxo aun sin la autorización del Consejo esto es, aceptar ese enfoque que vería en ellas una conducta "ilegal solo formal o aparentemente pero moralmente legítima" ${ }^{89}$, sin proclamar que debería ser el mismo Derecho Internacional el que consagrara esta posibilidad siempre que se diesen los presupuestos, porque el Derecho no solo debe el patrón de la legalidad sino también el de la moralidad, máxime cuando es el mismo Derecho el que reconoce, y con el mismo rango, que si está prohibido usar la fuerza en las relaciones internacionales también lo está cometer genocidios o atrocidades a gran escala ${ }^{90}$; siendo ambas prohibiciones normas sustantivas, de fondo, primarias del Derecho internacional ${ }^{91}$.

¿Debemos seguir anclados en la tesis que la CIJ adoptó en el asunto Nicaragua (1986), al afirmar que aunque Estados Unidos pudiera alegar el respecto de los derechos humanos como base para intervenir, "el empleo de la fuerza no es el método apropiado para vigilar o asegurar ese respeto"? ${ }^{92}$. ¿Debemos hacerlo siempre y en todo caso, pasados 18 años desde estas palabras y, sobre todo, desde la aceptación universal de que la prohibición del genocidio, la depuración étnica o los crímenes masivos de guerra o de lesa humanidad forman parte del "núcleo duro" del Derecho internacional imperativo?

Es importante y bienvenida sea la convicción de que la comunidad internacional no puede permitir ya dejar sin protección a los civiles en un contexto de conflicto armado o de crisis de las estructuras del Estado, en el que la Organización de Naciones Unidas esté presente con misiones $\mathrm{u}$ operaciones de mantenimiento de la paz. Bienvenidas sean la convicción y su puesta en práctica.

Y, sin embargo, esta respuesta dejará sin ella los casos en los que en esos mismos supuestos, que no son estrictamente aquellos para los que la Responsabilidad de Proteger se pensó, o en otros en los que el peligro, o su comisión misma, de atrocidades se diera, Naciones Unidas no intervenga porque uno (al menos) de los miembros permanentes del Consejo de Seguridad ha interpuesto su veto.

\footnotetext{
${ }^{89}$ En relación directa con esta cuestión, Dapo Akande piensa que "es posible considerar que el derecho debería prohibir dicha acción pero que hay casos en que la misma debería tener lugar (como una cuestión de moralidad) aunque la prohibición permaneciera". Y añade: "desde este enfoque, sería plausible tomar la postura de que aunque una acción en Siria fuera ilegal debería sin embargo llevarse a cabo" ("The legality of military action in Syria: humanitarian intervention and responsibility to protect", EJIL Talk (28 de agosto de 2013), p. 3, en http://www.ejiltalk.org).

${ }^{90}$ En este mismo sentido, nos parece, se manifiesta la profesora López-Jacoiste Díaz, E: "Repensando el sistema de seguridad colectiva..." op. cit., pp. 137, 141.

${ }^{91}$ Y no sustantiva, de fondo, primaria una (la prohibición del genocidio o de la tortura u otras que forman parte del ius cogens internacional) y procesal, instrumental, secundaria la otra (la que consagra la inmunidad de jurisdicción del Estado), argumento que se ha utilizado, sabido es, por la jurisprudencia internacional para entender que incluso cometiéndose por un Estado actos ex iure imperii contrarios al ius cogens, la naturaleza de la violación cometida no puede superar el principio (de otra naturaleza) de la inmunidad de jurisdicción (vid. ad ex. Gutiérrez Espada, Cesáreo. y Cervell Hortal, María.José (2012): El Derecho Internacional en la encrucijada, Trotta, Madrid [ $3^{\mathrm{a}}$ edición], pp. 84-87).

${ }^{92}$ Sentencia de 12 de junio de 1986, párrafo 268. Por más que haya autores que consideren esta es aún la idea defendible, como Marcelo Koohen: "The principle of non-intervention 25 years after the Nicaragua Judgment", Leiden JIL, $\mathrm{n}^{\mathrm{o}} 25$ (2012), p. 164.
} 


\section{El triunfo (¿?) de la Política (el Consejo de Seguridad y el capítulo VII: tarde y poco. :Y otras organizaciones internacionales?)}

El momento más crítico llegaría el 21 de agosto de 2013, cuando tuvo lugar un ataque químico en las afueras de Damasco que provocaba 1400 muertos. La línea roja que el Gobierno estadounidense había marcado como límite para desencadenar ataques contra Siria ${ }^{93}$ no tendría, sin embargo, las consecuencias anunciadas. El presidente Obama, adoptando un procedimiento nada habitual, anuncia el 31 de agosto que llevaría la posible invasión al Congreso; sin embargo, el 9 de septiembre da marcha atrás y decide sopesar la opción rusa, que evitaba una intervención a cambio de que Siria aceptara el control internacional de su arsenal químico. Ni siquiera el empleo de este armamento, cuya prohibición goza de carácter consuetudinario y que tan denostado ha sido en general por la comunidad internacional en las últimas décadas, conseguía dar un giro radical a la situación. Al día siguiente, el gobierno de Bashar al-Assad daba el visto bueno al plan, lo que permitió poco después (14 de septiembre), que Rusia y Estados Unidos firmaran un acuerdo para el control sobre el armamento químico por el cual presentan al Consejo Ejecutivo de la OPAQ de un proyecto de Decisión con procedimientos especiales para la destrucción y verificación del armamento sirio ${ }^{94}$. No habría intervención en Siria pero, en un intento de acallar las críticas, se optaba por una solución alternativa, en la que Rusia ganaba, además, puntos como mediador pacífico de conflictos y Estados Unidos se limitaba a aparecer en un discreto segundo plano.

El 14 de septiembre Siria consentía en adherirse a la Convención para la Prohibición y Eliminación de las Armas Químicas (2003), quedando así obligada a la verificación que el texto prevé para los Estados miembros.

El proceso lo culminaría la resolución 2118 (2013), de 27 de septiembre, que condenaba expresamente el empleo de armas químicas en territorio libio, calificándolo de amenaza para la paz y seguridad internacionales, declaraba que Siria debería renunciar a cualquier empleo, desarrollo, producción adquisición, conservación o transmisión de las mismas, y acogía el Acuerdo Marco para la Eliminación de Armas Químicas previamente acordado en Ginebra y que incluía un procedimiento especial de destrucción y control del armamento químico sirio. La resolución, que no se adoptó oficialmente bajo el capítulo VII de la Carta, aunque centraba la mayor parte en hacer suyo (pidiendo, por tanto, su aplicación) el acuerdo de su contenido en el proceso de destrucción y vigilancia del armamento químico, reflejaba varias cuestiones más:

- El empleo de armas químicas, declaraba su párrafo 1, es una amenaza para la paz y seguridad internacionales, su uso supone una violación del Derecho Internacional (párrafo 2) y Siria no debe emplear, desarrollar, producir, adquirir ni conservar armas químicas, ni transmitirlas a otros Estados o agentes no estatales (párrafo 4). De esta manera, el Consejo de Seguridad recordaba que la prohibición de empleo de las armas químicas era una norma consuetudinaria, cuyo incumplimiento (que por otro lado supone la violación de algunos de los principios básicos del Derecho Internacional Humanitario, como la prohibición de causar daños superfluos o sufrimientos innecesarios o la prohibición de armamento de efecto

\footnotetext{
${ }^{93}$ En una comparecencia ante la prensa en la Casablanca, el 20 de agosto de 2012, el Presidente Obama afirmó "We have been very clear to the Assad regime, but also to other players on the ground, that a red line for us is we start seeing a whole bunch of chemical weapons moving around or being utilized," the president said a year ago last week. That would change my calculus. That would change my equation." (abcnews, 26 de agosto de 2012; véase también, en general, la prensa del 21 de agosto de 2012).

${ }^{94}$ El Informe Final de la Misión de Naciones Unidas que investigó el posible uso de armas químicas se publicó con fecha 13 de diciembre de 2013 (infra nota 97). El Consejo Ejecutivo de la OPAQ adoptada esa decisión pocos días después (doc. EC-M-33/DEC.1, de 27 de septiembre de 2013).
} 
indiscriminado), podía tener consecuencias. Sin embargo, y como señalaremos, no tan graves como quizás hubiera merecido una actuación de esta naturaleza.

- La resolución hace suya la decisión del Consejo Ejecutivo de la OPAQ de 27 de septiembre de 2013, adoptada a instancias de lo acordado entre EEUU y Rusia, y decide que Siria debe cumplirla. De hecho, figura como anexo a la resolución, estableciéndose en la misma que la destrucción y control de las armas químicas se llevará a cabo por la OPAQ, apoyada por Naciones Unidas y, en particular, por los gobiernos estadounidense y ruso. El proceso incluía una serie de inspecciones in situ que concluirían en noviembre de 2013, fecha en la que se iniciaría la destrucción que a priori debería finalizar en junio de 2014. Los plazos, como era previsible, han sufrido retrasos 95 .

- El Consejo de Seguridad recuerda además a los Estados su obligación de denunciar cualquier violación de la resolución $1540(2004)^{96}$ si detecta alguna adquisición por agentes no estatales de armas químicas, sistemas vectores y materiales conexos.

- La resolución aboga por la convocatoria de una conferencia internacional sobre Siria. Este proceso, iniciado en realidad el 30 de junio de 2012 en Ginebra, se ha prorrogado con conversaciones sucesivas de las partes y convocatorias de Conferencias de paz auspiciadas por varios Estados y Naciones Unidas, ninguna de las cuales ha llegado, de momento, a un final feliz.

Dos cuestiones básicas dejaba en el tintero la resolución 2118 (2013): la intervención armada, o al menos, la imposición de medidas coercitivas, en caso de incumplimiento y la responsabilidad individual por los crímenes de guerra cometidos en Siria; las abordamos seguidamente.

Aunque el Consejo de Seguridad, según puede leerse en su Informe anual a la Asamblea General (2012-2013), ha consagrado veintiocho sesiones a la cuestión y publicado cuatro declaraciones a la prensa, ha sido incapaz de tomar decisión alguna directamente referida a evitar la catástrofe humanitaria. Sólo tras el uso de armas químicas ${ }^{97}$ fue capaz de adoptar su resolución 2118 (2013), de 27 de septiembre, en la que ni siquiera se prevén (de ser preciso) medidas contundentes, acordes con la necesidad y gravedad del caso en el supuesto de incumplimiento por las partes en el conflicto de la resolución, sino la fórmula de siempre y vuelta a empezar (...).

\footnotetext{
${ }^{95}$ Eran ciertamente ajustados si tenemos en cuenta varios datos comparativos: EEEUU y Rusia, dos de los Estados con mayor arsenal químico, deberían haber finalizado su destrucción en 2007, pero la imposibilidad de hacerlo les obligó en su día a solicitar una prórroga hasta 2012 (que ha sido, además, incumplida). Se supone que Siria tiene un arsenal químico similar al de la India, país que dedicó doce años a acabar con ellas. Por otro lado, los inspectores han tenido que trabajar en un entorno ciertamente complicado, con no pocos arsenales sitos en las zonas de combate. Para detalles al respecto, véanse los informes periódicos del Director General de la OPAQ (ad. ex., Note by the Director-General on Progress in the elimination of the Syrian chemical weapons Programme, doc. EC-M-38/DG.1, de 30 de enero de 2014).

${ }^{96}$ En dicha resolución se afirma que la proliferación de las armas nucleares, químicas y biológicas, así como sus sistemas vectores, constituye una amenaza a la paz y la seguridad internacionales. La resolución obliga a los Estados, entre otras cosas, a abstenerse de suministrar cualquier tipo de apoyo a los agentes no estatales que traten de desarrollar, adquirir, fabricar, poseer, transportar, transferir o emplear armas nucleares, químicas o biológicas y sus sistemas vectores.

97 "United Nations Mission to investigate allegations of the use of chimical weapons in the Syrian Arab Republic", Final Report, p. 18 (párr. 108) "The United Nations Mission concludes that chemical weapons have been used in the ongoing conflict between the parties in the Syrian Arab Republic", en https://unoda-web.s3.amazonaws.com/wp-content/uploads/2013/12/report.pdf.
} 
La inacción del Consejo en el caso de Siria no sólo es la opinión que personalmente defiendo, y con absoluta convicción ${ }^{98}$, también ha sido manifestada con claridad en el seno de Naciones Unidas por los Estados miembros, tanto con palabras como con hechos:

- Palabras como las de Alemania, al debatirse en la Asamblea General el Informe del Consejo de Seguridad 2012-2013, estimando que los vetos planteados a los proyectos de resolución sobre Siria plantean la interrogante de la pertinencia del Consejo tal y como hoy es y añadiendo que la propuesta francesa de auto-regulación del derecho de veto y su renuncia en caso de crímenes en masa merecía ser estudiada más adelante. O las de las Islas Maldivas, en la misma sede, pidiendo la prohibición del derecho de veto en situaciones en las el Consejo se enfrente a crímenes masivos, porque, añadía el representante de este país, si los Estados miembros no son capaces de proteger a sus ciudadanos, Naciones Unidas debe asumir esta responsabilidad 99

- Y hechos, como el de Arabia Saudí, que habiendo sido elegida como miembro no permanente del Consejo, renunció al día siguiente aludiendo a la incapacidad de este órgano para hacer frente a sus responsabilidades para con la paz mundial y citando expresamente, el texto difundido por la agencia nacional de noticias SPA, su (in)acción en el caso de la guerra civil en Siria ${ }^{100}$. El 6 de diciembre de 2013, la Asamblea General elegía a Jordania en sustitución de Arabia Saudí; el Centro de Noticias de Naciones Unidas que informaba del hecho destacó expresamente que la renuncia de Arabia Saudí se explicó por este país:

"por no estar de acuerdo con la actuación del Consejo con respecto a la situación en Siria..."101.

Es cierto que el párrafo 21 de la resolución 2118 parecía dejar abierta la puerta a futuras actuaciones, en tanto en cuanto establecía:

"[El Consejo de Seguridad] Decide que, en caso de incumplimiento de lo dispuesto en la presente resolución, incluida la transferencia no autorizada de armas químicas, o de cualquier empleo de armas químicas por cualquier persona la república Árabe Siria, impondrá medidas en virtud del capítulo VII de la Carta de las Naciones Unidas"

Pero tal posibilidad nunca se ha materializado; el mismo tenor de la resolución lo auguraba: no hay una amenaza auténticamente creíble de sanciones mayores (y no digamos de

\footnotetext{
${ }^{98}$ La opinión doctrinal mayoritaria parece compartir este planteamiento: vid. ad ex. Pons, Rafols, Xavier.: "Naciones Unidas y Siria: idea y realidad", op. cit., pp. 5-14; Andrés Sáenz de Santamaría, Paz: "Las Naciones Unidas ante el conflicto de Siria”, op. cit., pp. 1-15; Domestici-Met, Marie-José., op. cit., pp. 879-881; Weckel, Philippe: "Crise en Syrie, la relance du processus politique", op. cit., pp. 1-12 (y en las pp. 11-12 se citan otras 18 contribuciones del profesor Weckel al tema a lo largo de estos dos años, 2011-2013); Bermejo García, Romualdo.: "La responsabilidad de proteger y el Derecho internacional...", op. cit., pp. 203-209. Incluso quienes como Dapo Akande manifiesta tajantemente la inadmisibilidad en el Derecho internacional vigente de una intervención humanitaria sin autorización del Consejo de Seguridad, lo que como hemos apuntado no se ha dado en el caso de Siria, afirma: "Ii is possible to take the view that the law should prohibit such action but that there are cases where such action should occur (as a matter of morality) although the prohibition remains in place (...) On this view, it would be plausible to take the view that even if action y Syria is unlawful it should nevertheless take place"("The legality military action in Syria...", op. cit., p. 3).

${ }^{99}$ Véase Brusil Miranda, Metou.: "L' Assemblée générale critique les méthodes de travail et le fonctionnement du Conseil de Sécurité”, Bulletin Sentinelle, n 368, 1 diciembre 2013, p. 6.

100 Ángeles Espinosa, 18 de octubre de 2013, en http://www.internacional.elpais.com.

${ }^{101}$ Centro de Noticias de la ONU, en http://www.un.org. La interpretación que hago de la motivación que llevó a Arabia Saudí a renunciar a su puesto como miembro no permanente del Consejo ha sido defendida también, leemos escritas ya estas líneas, por Jane Kinninmont, "The Syrian Conflict and the Geopolitics of the Region”, op. cit., p. 3.
} 
intervención armada) en caso de incumplimiento porque, por más que algunos Estados (Francia, Reino Unido y EEUU) lo intentaron, no se refleja en su texto una autorización inmediata para que los Estados actúen en caso de que así sea, sino la mera posibilidad de que el Consejo vuelva a reunirse para sopesar medidas más contundentes o, en su caso, el empleo de la fuerza armada, con lo que habría que acometer la redacción de una nueva resolución, debatirla y conseguir que ninguno de sus miembros permanentes imponga su veto ${ }^{102}$. Difícil $^{103}$.

Siria salía, ciertamente, bien parada con esta opción, en tanto en cuanto si cumplía lo exigido que, recordemos, se limitaba al ámbito de las armas químicas, nada tendría a priori que temer. El Consejo de Seguridad, por su parte, volvía a revelarse como el mecanismo que es, claramente insuficiente y limitado por el derecho de veto. La Responsabilidad de Proteger había sido en este caso totalmente ignorada, corriéndose incluso el riesgo (con una respuesta tan "medida" o tan comedida) de banalizar la prohibición del uso de las armas químicas ${ }^{104}$.

Desde que se aprobara la resolución, las cifras de fallecidos y desplazados en el conflicto sirio ha seguido aumentando, sin que ello pareciera conmover al Consejo de Seguridad. El 22 de febrero de 2014 conseguía, al fin, aprobar, por unanimidad además, la resolución $2139^{105}$, en la que condena enérgicamente las violaciones generalizadas de los derechos humanos y del derecho internacional humanitario cometidas por todas las partes en el conflicto (párrafos 1 y 2). El párrafo 3 se centra en la protección de la población civil, pero obviando la doctrina de la Responsabilidad de Proteger, que esta vez no aparece ni siquiera en el Preámbulo: el Consejo de Seguridad vela por los civiles, sí, pero se ajusta a la esfera del derecho internacional humanitario, considerando sin más la crisis siria como un conflicto armado en el que deben por tanto primar estas normas:

\begin{abstract}
"Exige que todas las partes pongan de inmediato fin a todos los ataques perpetrados contra civiles, así como al uso indiscriminado de armas en zonas pobladas (...) y recuerda a este respecto la obligación de respetar y asegurar el respeto del derecho internacional humanitario en todas las circunstancias y recuerda también, en particular, la obligación de hacer una distinción entre la población civil y los combatientes, y la prohibición de cometer ataques indiscriminados y ataques contra civiles y bienes de carácter civil”.
\end{abstract}

La resolución era acogida por los medios e incluso en el seno del órgano que la aprobó como un gran hito, pero no me parece que merezca tal honor si nos atenemos a su contenido:

\footnotetext{
102 Algunos autores como Stahn, Carsten.: "Syria, Security resolution 2118 (2013) and peace versus justice: two steps forward, one step back", EJIL Talk, 3 de octubre de 2013, han remarcado la diferencia con lo ocurrido, por ejemplo, en el caso iraquí, en el que la resolución 1441 (2002), invocada en conjunción con la 678 (1990) para justificar el uso de la fuerza, afirmaba que, en caso de incumplimiento (también por desarme) Irak se enfrentaría a serias consecuencias (párrafo 13).

${ }^{103}$ En el mismo sentido Kinninmont, Jane, “The Syrian Conflict and the Geopolitics of the Region” op. cit., pp. 3-4.

${ }^{104}$ Sobre Siria y las armas químicas, Bautista Hernáez, Andrés.: "Siria y las normas de Derecho Internacional sobre armas químicas: ¿una solución al conflicto?”, Documento de Opinión 111/2013, Instituto Español de Estudios Estratégicos (12 de noviembre de 2013), en http://www.ieee.es y Anderson, Kenneth: "Legality of intervention in Syria in response to chemical weapon attacks", ASIL Insights, vol. 17 (30 de agosto 2013), p. 21, disponible en http://www.asil.org/insights/volume/17/issue/21/legality-intervention-syria-response-chemicalweapon-attacks.

${ }^{105}$ Para el texto de la resolución 2139 (2014) y un comentario valorativo de la misma, pero también sobre el contraproyecto ruso de 13 de febrero y el proyecto inicial de Jordania, Australia y Luxemburgo de 6 de febrero (que Rusia rechazó) vid. Weckel, Philippe: "Syrie: la Russie et la Chine soutiennent l' adoption de la Résolution CS 2139 du 22 février 2014”, Bulletin Sentinelle, $\mathrm{n}^{\circ}$ 379, 23 de febrero de 2014, pp. 1-28, en http://www.sentinelle-droit-internationale.fr/.
} 
simplemente exige a las partes que permitan el acceso de la asistencia humanitaria de los organismos de Naciones Unidas y el cumplimiento de medidas para asegurar la asistencia sanitaria y la protección de la población civil. Es cierto que el párrafo 9 in fine recuerda a Siria que a ella corresponde la responsabilidad principal de proteger a su población, pero no deja opción a sopesar otras medidas en caso de que, como lleva haciendo cerca de tres años, continúe sin hacerlo. No parece, en definitiva, que sea una resolución que vaya a lograr una mejora sustancial de la estabilidad en Siria (el tiempo, con todo, desmentirá o confirmará nuestras palabras) y los debates en el seno del Consejo con motivo de su aprobación han dejado nuevamente entrever la división de opiniones entre sus miembros: mientras algunos (Australia, Estados Unidos, Reino Unido y Lituania) ${ }^{106}$ se mostraban dispuestos a tomar medidas adicionales en el caso de que no se respetara, otros adoptaban una postura más cauta, bien callando al respecto (caso chino) o recalcando de manera expresa (caso ruso) ${ }^{107}$ que la resolución no supone una imposición automática de sanciones, porque el Consejo de Seguridad (el veto de Rusia, son quizás las palabras que debería haber empleado su representante para ser exacto) no lo habría permitido. El representante de Luxemburgo declaraba, en los debates de la resolución que, "para crédito del Consejo, el derecho internacional humanitario y las necesidades del pueblo sirio han prevalecido por encima de los intereses de quienes se aferran al poder en Siria" ${ }^{208}$. ¿Es realmente creíble?

Cuando se lee el Informe de la Oficina del Alto Comisionado de Naciones Unidas sobre los Refugiados, hecho público el 22 de agosto de 2014, seis meses después por tanto de la resolución 2139 (2014), la respuesta es no ${ }^{109}$.

No ha sido mucho mejor el papel de las organizaciones regionales en Siria.

A) La Liga Árabe, que esta vez no presionó como hizo en Libia para intervenir en el país, sí suspendió a Siria en su condición de Estado miembro el 12 de noviembre de 2011 y le impuso sanciones días más tarde ${ }^{110}$, colaboró, asimismo, con Naciones Unidas en el nombramiento de un Enviado Especial y en el diseño de un plan de paz en noviembre de 2012 (también el Consejo de Cooperación del Golfo), y reconoció a la Coalición Nacional de la Oposición de Siria como el representante legítimo ante esos dos organismos, decantándose claramente por uno de los dos bandos.

B) En lo que respecta a la UE, su intervención ha sido muy limitada. Pero vayamos por partes. La UE empezó a mantener con Siria una importante relación desde el año 2008. Ya tenía con ella un Acuerdo de Cooperación (1977) ${ }^{111}$, pero es desde finales de 2008 cuando la Unión se

\footnotetext{
${ }^{106}$ Doc. S/PV.7116, 22 de febrero de 2014. Australia (p. 4): "el Consejo espera que se cumplan sus exigencias y que habrá consecuencias por su incumplimiento. Seguiremos firmes en ello". Estados Unidos (p. 6) : “La resolución es importante por dos motivos. En ella se exige claramente la adopción de medidas específicas y concretas, y constituye un compromiso de actuar en caso de incumplimiento". Reino Unido (p. 9) :’El Consejo de Seguridad estudiará la situación humanitaria cada 30 días y, tal como se deja claro en la resolución, tenemos la plena intención de tomar medidas adicionales si se hace caso omiso a las exigencias establecidas en la resolución". Lituania (p. 14): "el Consejo puede y debe estar dispuesto a adoptar las medidas ulteriores que hagan falta en caso de que las partes en el conflicto no atiendan el llamamiento contenido en la resolución".

107 Doc. S/PV.7116, 22 de febrero de 2014 (p. 8). Afirmó, con todo, que "El Consejo de Seguridad, independientemente de los progresos que se han logrado mediante esta resolución y su aplicación por todas las partes, puede considerar la posibilidad de adoptar nuevas medidas".

108 Doc. S/PV.7116, cit., p. 3. Francia también afirmaba (p. 5) que con la aprobación de esta resolución, "el Consejo de Seguridad evita la deshonra del silencio". La del silencio sí; la de afrontar la situación con responsabilidad, podríamos añadir, no.

${ }^{109}$ Vid. Megan, Price, Ghodes, Anita y Ball, Patrick: Updated Statistical Análisis of Documentation of Killings in the Syrian Arab Republic, Human Rights Data Analysis Group (August 2014), pp. 1-26, en http://www.ohchr.org/Documents/Countries/SY/HRDAGUpdatedReport.Aug2014.pdf)

${ }^{110}$ Res. 7442 de la Liga Árabe de 27 de noviembre

${ }^{111}$ DOUE, L 269, 27 de noviembre de 1978.
} 
pone de acuerdo y ve en Siria un país clave en no pocos problemas de Oriente Medio. Así, se relanza en dicho año la negociación con este país para la firma de un Acuerdo de Asociación, que en octubre de 2009 estaba, por parte de la UE listo para su firma; se incita a y se recibe con complacencia por la Unión la participación de Siria en la Cumbre de París de julio de 2008 y en el proceso por tanto de la Unión para el Mediterráneo; y, en fin, se incluye a Siria en la Política Europea de Vecindad con las ventajas que ello supone ${ }^{112}$. Tras empezar a conocerse la violencia en la represión de las revueltas del régimen de Damasco, la UE inicia un proceso de reacción muy similar al que siguió en Siria: Suspende el Acuerdo de Cooperación (1977) y paraliza (2011) el proceso pendiente sobre el Acuerdo de Asociación ${ }^{113}$.

El 27 de mayo de 2013, el Consejo de Asuntos Exteriores deja perfectamente clara la posición de la UE sobre las dos partes que se enfrentan en Siria, al aceptar a la Coalición Nacional de Fuerzas Revolucionarias y de Oposición en Siria "como representante legítimo del pueblo sirio"114. Y el Parlamento Europeo, pide el 12 de septiembre de 2013, "que el Presidente Assad y su régimen dimitan y abran la vía de la transición democrática"115.

Adoptó también medidas coercitivas contra el régimen sirio. No en aplicación (como en Libia) de una resolución del Consejo de Seguridad, que no la hubo, pero sí por su propia decisión, tras el veto en el Consejo de Rusia y China a la adopción de medidas: en este sentido, prohibió la venta, trasferencia o exportación de armas o material para represión interna y, además, prohibió los viajes a territorio de Unión y congelación de activos y cuentas a miembros del Gobierno sirio y personas conectadas con él ${ }^{116}$, incluyendo a algunos familiares, como a la hermana del líder sirio, Bouchra Al-Assad ${ }^{117}$.

La UE está prestando, sin duda, al pueblo sirio una importante ayuda en varios frentes: de un lado, la UE y sus Estados miembros son, hoy, los mayores contribuyentes del Mundo en ayuda humanitaria para el pueblo sirio en Siria, para los refugiados de este país en Estados vecinos y aún para los estudiantes sirios en Europa ${ }^{118}$; de otro, la UE ha decidido aportar su ayuda financiera para contribuir a la destrucción del armamento químico sirio, concertado el contrato pertinente al efecto con la OPAQ ${ }^{119}$.

\footnotetext{
112 Véase "European Neighbourhood and Partnership Instrument Syria Arab Republic. National indicative Programme 2001-2013", pp. 1-33.

${ }^{113}$ Véase Decisión del Consejo de 2 de septiembre de 2011, DOUE L 228, de 3 de septiembre de 2011.

114 Council conclusions on Syria 3241 st. Foreign Affairs Council meeting, Brussels, 27 may 2013 (http://www.consilium.europa, Newsroom, pp. 1-3, punto 3).

${ }^{115}$ Resolución sobre Siria (2013/2819 [SSP]), P7_TA (2013) 0378, párrafo 6. Ya lo había hecho el año anterior, en su resolución de 16 de febrero de 2012 (P7-TA [2012]0057).

${ }^{116}$ Véase reglamento 442/2011, de 9 de mayo y decisión del Consejo 2011/273/PESC de 9 de mayo (DOUE L 121, 10 mayo 2011).

${ }^{117}$ La inclusión de la hermana del Presidente de Siria en la lista de personas a las que se aplicaba la prohibición de viajar y la congelación de activos, motivó el que esta presentara un recurso contra la misma. El Tribunal General de la UE ), en su sentencia de 12 de marzo de 2013 (case T-202/12 Bouchra Al-Assad v. Consejo) rechazó su petición (vid supra nota 2).

${ }^{118}$ Más de 1.9 billones de euros ha movilizado ya la UE con este objetivo. Para ayudar a los 9 millones de sirios (más del 41\% de la población del país según los datos de 2012 del Banco Mundial) que, en Siria, necesitan de ayuda y asistencia humanitaria (y más de 6 millones de los cuales viven desplazados de sus hogares, en otras ciudades del país o en campamentos); para ayudar a los casi 3 millones de sirios refugiados en el Líbano (casi 1 millón), Turquía (600.000), Jordania (más de 500.000), Iraq (250.000)...; para ayudar, en fin, a que los estudiantes Erasmus sirios puedan continuar sus estudios en Universidades europeas "'Syria crisis: EU delivers on its pledges and movilices another euros 8.5 million for Syria and Jordan", European Commission Press Release, IP/13/999, Brussels (28 de octubre de 2013), pp. 1-3; "Syria crisis: UN Security Council resolution adopted on humanitarian situation", European Commission, Statement/14/18, Brussels (22 de febrero 2014),

${ }^{119}$ Véase "EU to support the destruction of syrian Chemicals stockpiles", European Commission Press Release, IP/14/151, Brussels (17 de febrero de 2014), pp. 1-2.
} 
Y prácticamente esto es todo (sin que sea poco). La UE ni siquiera se ha planteado el envío de misión alguna a la zona, posiblemente teniendo tan fresco el recuerdo de lo que ocurrió con su misión EUFOR Libia. A fortiori, la Unión no estuvo nunca del lado de quienes se plantearon, tras el ataque químico de 28 de agosto de 2013, y en un primer momento una intervención armada (Estados Unidos, Francia o el Reino Unido). Muy pocos días después de esa fecha, y entre el tam-tam de los tambores de guerra en Washington, Londres o París, el Presidente del Consejo Europeo, Herman Van Rompuy, en la reunión del G-20 en San Petersburgo (Rusia) declaraba la necesidad de una solución a la crisis siria en el marco de un estricto respeto de la Carta de Naciones Unidas (...) ${ }^{120}$; se imponía así, en el seno de la UE una posición moderada, que parecía alejarse del sentir del mismo Parlamento Europeo en su resolución de 12 de septiembre de $2013^{121}$.

\title{
4. Conclusión
}

Tres conclusiones cabe sacar, entiendo, de todo lo expuesto:

Una, la catástrofe humanitaria de Siria constituye sin duda una amenaza para la paz y seguridad internacionales y, además o en todo caso, en ella se cumplen las exigencias básicas y previas para la aplicación del concepto de la Responsabilidad de Proteger.

Dos, el Consejo de Seguridad hubiera debido, basándose en uno u otra (capítulo VII, Responsabilidad de Proteger), y habiendo aprendido de los errores que en la práctica se cometieron al aplicar su resolución 1973 (2011), detener antes el conflicto para proteger a la población civil. No lo ha hecho. El veto (o su amenaza) de Rusia y de China lo han impedido. El Secretario General de Naciones Unidas ha reconocido en su Informe de 2013 sobre la aplicación de la Responsabilidad de Proteger el daño que esta parálisis institucional ha causado:

\begin{abstract}
"Nuestra inacción colectiva para prevenir los crímenes atroces en la República Árabe Siria durante los últimos dos años y medio seguirá siendo una pesada carga moral para el prestigio de las naciones Unidas y sus Estados Miembros, en particular los que tienen la responsabilidad primordial de la paz y la seguridad internacionales... $" 122$.
\end{abstract}

Tres, el concepto de Responsabilidad de Proteger necesita, para poder cumplir su función, dado como ha sido estructurado, la modificación de los parámetros que rigen el derecho de

\footnotetext{
120 "Siria: Unión Europea dividida sobre postura ante la guerra", Gestión, 5 de septiembre de 2013, en http://gestion.pe.

${ }^{121}$ En ella, y teniendo presente el uso de las armas químicas de 28 de agosto de 2013 a las afueras de Damasco, que causó más de 800 muertos, entre ellos no pocos niños y mujeres, respecto del cual (a diferencia del Informe de la Misión de Naciones Unidas enviado a la zona, que no se pronuncia sobre la autoría del ataque) el PE defiende que "parece haber pruebas suficientes de que el régimen sirio es el responsable de esos ataques" (considerando B), el Parlamento pide "una respuesta inequívoca, enérgica, focalizada y colectiva, sin excluir la aplicación de medidas disuasorias..." (párrafo 2). Solicita en particular "a Rusia y China que, en cuanto miembros permanentes del Consejo de Seguridad de las Naciones Unidas, asuman su responsabilidad y ayuden a encontrar una posición común y una solución a la crisis siria" (párrafo 6). E invoca, incluso, la posibilidad (¿pensando acaso en la resolución 377 [V] "Unión para la Paz" de 1950?) de acudir a vías alternativas a una inacción del Consejo: "sin excluir la participación de la Asamblea General de Naciones Unidas, que podría ocuparse del asunto en caso de que se registrara una situación de bloqueo sistemático en el Consejo de Seguridad" (párrafo 6) (Resolución del PE de 12 de septiembre de 2013 sobre la situación de Siria [2013/2819 [RSP]), P7_TA [2013] 0378).

122 "La responsabilidad de proteger: responsabilidad del Estado y prevención. Informe del Secretario General" (A/67/929-S/2013/399) (9 de julio de 2013), pp. 1-19, párr. 73.
} 
veto de los miembros permanentes del Consejo de Seguridad. No en vano ha comenzado a extenderse una nueva iniciativa que aboga por la "responsabilidad de no vetar" 123 .

Y es que entender que sólo con autorización del Consejo la comunidad internacional puede reaccionar, cuando sea el caso, incluso mediante una intervención armada por causa de humanidad, sin la modificación del derecho de veto, lo que permitiría (como el caso de Siria ha demostrado) que la masacre de miles de personas se produzca en un Estado protegido por uno de los miembros permanentes del Consejo y por lo tanto que se siga considerando que la soberanía nacional es el principio supremo del Derecho internacional y está por encima del que protege la vida y los derechos fundamentales del ser humano, sería (por utilizar las palabras que hace ya años proclamara un internacionalista alemán) "privar al Derecho Internacional de todo su valor esencial" 124 .

Es por ello que la propuesta de Francia, pidiendo de la adopción de un código de conducta que implique, en los supuestos apuntados ya, la renuncia del derecho de veto en estos casos de los miembros permanentes del Consejo, constituye una excelente oportunidad de colmar la laguna o cerrar la grieta que la adopción del concepto de Responsabilidad de Proteger por los Jefes de Estado o de Gobierno de los miembros de Naciones Unidas en la Cumbre del Milenio (septiembre 2005) implicó. Su adopción, con las sugerencias que he considerado con anterioridad, daría efecto útil por fin a este concepto.

Tres conclusiones y, si se me permite, algo más. Hoy por hoy, porque "todo cambia [y] nada permanece", el desenlace del conflicto en Siria pasaría, parece, por las Conferencias de Paz convocadas a tal efecto en Ginebra. La primera de ellas, en enero de 2014, fue precedida de una propuesta de alto el fuego ${ }^{125}$. Pudo haberse tomado antes otro camino que nos hubiera ahorrado mucha de la sangra derramada, pero si hay una posibilidad, aunque sea tarde, ahora, de poner fin a ese derramamiento, la comunidad internacional (y a su cabeza Estados Unidos y Rusia y Arabia Saudí y la República Islámica de Irán...) tienen el deber de "pelearlo"..., para conseguirlo. Y mucho y muy fuerte deberán hacerlo, ante el aparente fracaso de Ginebra2 y la negativa de Damasco de negociar un Gobierno de transición (en el que no deberá estar el actual líder sirio, salvo para los "peores ciegos", los que no quieren ver). ¿Se ha convencido algunos de que es hora ya de acabar con este tema? ¿Es un indicio de que la paciencia se agota, el que Rusia y China se hayan sumado en el voto a favor de la resolución 2139 (2014), de 22 de febrero, del Consejo de Seguridad, se han preguntado algunos analistas?.

Indicios aparte, el giro copernicano que el conflicto de Siria puede aún generar tiene que ver, y enlazo así, para acabar, con lo que al principio de este relato escribía, con ese Estado Islámico que se ha hecho fuerte a caballo entre Siria e Irak, que ordena la conversión al Islam o la muerte y que quiere, eso, la instauración de un Estado Islámico fundamentalista en la región y, parece, más allá (...). Pero, repárese, si el giro copernicano que parece se está gestando finalmente se produce, éste no parece venir de la mano de la comunidad internacional institucionalizada, ni del capítulo VII de la Carta, ni del Consejo de Seguridad, ni tampoco del concepto de la Responsabilidad de Proteger, sino de una coalición de Estados

\footnotetext{
${ }^{123}$ Propuesta por primera vez por Global Solutions en 2010: "The Responsibility not to veto: a way forward", pp. 1-12, en www.globalsolutions.org/files/public/documents/RN2V White Paper_CGS.pdf.

${ }^{124}$ Tomuschat, Ch: "International Law: ensuring the survival of mankind on the eve of a new century. General Course on Public International Law”, Recueil des Cours, n 281 (1999), p. 224.

${ }^{125}$ Estados Unidos y Rusia lo proponían en los días previos al inicio e Irán y Turquí lo habían hecho a fines de noviembre de 2013. "Irán y Turquía llaman a un alto el fuego en Siria”, Red Voltaire, 28 de noviembre de 2013, pp. 1-2, en www.voltairemet.org/article181245.html; "Estados Unidos y Rusia proponen alto el fuego en Siria", El Mundo, DW.DE, 13 de enero de 2014, en www.dw.de; "Estados Unidos y Rusia piden un alto el fuego 'limitado' en Siria a la región de Alepo”, EFE, 13 de enero de 2014, en www.jnn-digital.blogspot.com.es.
} 
liderada por los Estados Unidos ${ }^{126}$ que se considera objeto de una "amenaza inminente" y por tanto legitimado para un uso de la fuerza "en legítima defensa" (George Bush hijo, debe estar sonriendo en su rancho de Texas...) $)^{127}$.

\footnotetext{
${ }^{126}$ Que busca con insistencia (gira del Secretario de Estado en la segunda semana de septiembre) el apoyo de otros Estados, muy en particular de Estados Árabes de la zona. Arabia Saudí y Qatar, por ejemplo, ya han comunicado que ayudarán. También la Liga de estados Árabes. De algún modo, el Presidente Obama parece buscar una coalición parecida a la que el Presidente Bush (padre) consiguió para "remover" de Kuwait a Irak (“Guerra del Golfo, 1990-1991).

${ }^{127}$ Las primeras tomas de posición sobre la legalidad de eventuales bombardeos contra el Estados Islámico en territorio de Siria ya se han planteado. Véase Weckel, Ph.: "Coalition contre l'Etat-islamique-en-Irak: La legalité de frappes aériennes en Syrie en discusión”, Sentinelle, n'. 402, 14 de septiembre de 2014, pp. 1-6, en http://www.sentinelle-droit-international.fr.
} 